\title{
Hybrid Chiller Plant Optimization Strategies for Hotel Building on Nile River of Egypt
}

\author{
Tarek A. Mouneer ${ }^{1^{*}}\left(\mathbb{D}\right.$, Mohamed H. Aly $^{2}$ (1) \\ ${ }^{1}$ Mechanical Engineering Department, Benha Faculty of Engineering, Benha University, Benha, Egypt \\ ${ }^{2}$ Mechanical Power Engineering Department, Faculty of Engineering, Helwan University, Cairo, Egypt \\ Email: ^tarek.mouneer@bhit.bu.edu.eg,mohamed_hanafy@m-eng.helwan.edu.eg
}

How to cite this paper: Mouneer, T.A. and Aly, M.H. (2021) Hybrid Chiller Plant Optimization Strategies for Hotel Building on Nile River of Egypt. Journal of Power and Energy Engineering, 9, 61-88. https://doi.org/10.4236/jpee.2021.94005

Received: March 12, 2021

Accepted: April 27, 2021

Published: April 30, 2021

Copyright $\odot 2021$ by author(s) and Scientific Research Publishing Inc. This work is licensed under the Creative Commons Attribution-NonCommercial International License (CC BY-NC 4.0). http://creativecommons.org/licenses/by-nc/4.0/

\begin{abstract}
Hybrid chiller plants (HCPs) using multiple chillers and different energy sources are highly recommended in several energy applications in non-residential buildings such as hospitals and hotels. Time of use and cooling load profiles are significant factors that should be carefully considered either in chiller plant design or in chiller sequencing operation. This article aims to present an operation planning of HCP which consists of both electric and non-electric chillers. Four operational strategies are proposed and solved to compare their coefficients of performance and economics of running costs. A typical hotel building located on the Nile river in Egypt is selected to perform the current thermal and economic case study. The total cooling load profile of this hotel building is 4000 refrigeration tonnage (TR), which is simulated to optimize chiller sequence of operation and to select optimal design conditions of both numbers for electric and non-electric chillers used in HCP. The results of this comparative study for running cost are defined using various design configurations with different several chiller sequences available for each configuration. Then, the results of COPs, and operational running cost and initial cost are presented in this article also. The comparison aims to find the optimal design and operational sequencing for HCPs on thermal basis and economic analysis which were attached in this article. Recommendations and suggestions for future work are attached at the end of this article.
\end{abstract}

\section{Keywords}

Hybrid Chiller Plant, Sustainability in Buildings, Air-Conditioning, Hotel Building, Chiller Sequencing, Building Cooling

\section{Introduction}

Recently, several researches have been conducted to evaluate the energy con- 
sumption and methods of its rationalization in different types of buildings such as hotel buildings under different operating conditions. Smith [1] early focused on using different solving techniques for hybrid chiller plants using multiple chillers and different energy sources. Smith has early introduced the use of a hybrid chiller plant in 2002 for chillers manufacturing markets. Smith conducted economical comparative studies for a cost analysis for hybrid chiller plants to compare electrical consumption, and gas consumptions. This study used different design strategies to compare their cost estimation method.

Bodach et al. [2] presented the design guidelines for energy-efficient hotels in Nepal. Deng and Burnett [3] investigate the energy performance of hotel buildings in Hong Kong. Mardani et al. [4] used fuzzy multiple criteria decision-making approaches for evaluating energy-saving technologies and solutions in five-star hotels. Sheng et al. [5] studied the energy consumption model and reported energy benchmarks of five-star hotels in China. Jasmim et al. [6] presented criteria for assessing a sustainable hotel business. Kyriaki et al. [7] investigated energy and environmental performance using solar thermal systems in hotel buildings. Buso and Corgnati [8] customized modeling approach for multi-functional buildings for an Italian hotel. Kresteniti [9] presented a developed concept for energy optimization of existing Greek hotel buildings. Xing et al. [10] conducted energy efficiency analysis for hotel buildings in Tianjin, China using eQuest software. Priyadarsini et al. [11] investigated the energy performance of hotel buildings in Singapore. Yang et al. [12] presented design and simulation of gas turbine-based CCHP combined with solar and compressed air energy storage in a hotel building. Hafeez et al. [13] focused on the thermal performance study of double brick wall construction on the building envelope of a high-rise hotel in Malaysia. Wang [14] conducted a study on the energy performance of hotel buildings in Taiwan, China. Chung and Park [15] conducted a comparative study between building energy demand for hotels, hospitals, and offices in Korea. Gonc et al. [16] studied energy and exergy-based indicators for the energy performance assessment of a hotel building.

Several researchers conducted their important concern on the optimal design of chiller plant and chiller sequencing. Cheng et al. [17] presented a probabilistic approach for the uncertainty-based optimal design of chiller plants in buildings. Karami and Wang [18] stress the importance on optimal control operation of an all-variable speed water-cooled chiller plant using particle Swarm optimization. Wang [19] investigated an empirical model for evaluating the power consumption of centrifugal chillers. Wang [20] also conducted a steady-state empirical model for evaluating energy-efficient performance of centrifugal water chillers. $\mathrm{Yu}$ and Chan [21] conducted an assessment of the operating performance of chiller systems using cluster analysis, which is a statistical tool used to identify groups of variables. They stated that to prioritize the critical variables influencing the system COP. Zheng et al. [22] improved the artificial fish swarm algorithm for energy saving for optimal chiller loading. Zhuang et al. [23] presented 
a risk-based robust optimal chiller sequencing control strategy for energy-efficient operation considering measurement uncertainties. Liao et al. [24] conducted uncertainty analysis for chiller sequencing control. Liao et al. [25] presented robustness enhancement for chiller sequencing control under uncertainty. Lu et al. [26] studied the optimization of chiller loading using an adaptive Neuro-Fuzzy inference systems and genetic algorithms. Recently, Shirazi et al. [27] present a comprehensive and critical review on solar-powered absorption chillers. Afzali and Mahalec [28] comprise optimal design, operation, and analytical criteria for determining optimal operating modes of a chiller plant with a fired boiler, electric chiller, and absorption chiller. More recently, Ho and Yu [29] suggest improved models and optimization for the energy performance of chiller systems with diverse component staging. Li and Yao [30] add to these studies the modeling of heating and cooling energy demand for building stock using a hybrid approach. Yu and Chan [31] investigated the optimum load sharing strategy for multiple-chiller systems serving air-conditioned buildings. Their aim was to further develop optimum load sharing strategies for multiple chillers in order to maximize their aggregate COP. This paper first considers using a sophisticated chiller model to analyze how the chiller load interacts with the COP under various ambient conditions and at different strategies for controlling the condensing.

The literature reveals that several kinds of research have been demonstrated the energy efficiency for buildings such as hotel and hospital buildings using different chiller plant, and several operating strategies using many approaches. The optimum load sharing strategies for multiple chillers can significantly maximize the COP values and reduce the running costs of the multiple chillers plant. However, a few numbers of researches has been available on using hybrid chiller plant consists of both electrical and non-electrical chillers in their chiller plant. The current article objective focuses on using a hybrid chiller plant for a typical hotel building located in Egypt and based on different inputs for energy sources commonly utilized in the local Egyptian market.

The article aims to present a new method for hybrid chiller plant optimal design, and operational planning which consider helpful for the decision-making process, either during design stages or during operation stages. A selected design option based on both electrical-driven and gas-driven chillers, with the same sharing load percentage, is to simulate the real chiller sequencing loading in a hybrid chiller plant. The rest of the paper is organized as follows. Section 2 presents the research methodology, description of the tested hybrid chiller plant, and the specifications of the simulated numerical model of the proposed hybrid chiller plant, which consists of two electrical chillers and two non-electrical (Natural Gas) chillers. Section 2 also presents the proposed algorithm and the basic principle equations of the operational costs of electrical consumptions, gas consumption, and water consumptions are presented. In Section 3, numerical experiments are defined to show the applications of the hybrid chiller plants. The results and discussion of this numerical simulation are presented in Section 
4. Section 5 concludes the findings of these results, recommendations and suggestions for future work.

\section{Methodology}

In this section, some basic specifications for the proposed hotel building architecture are defined. The current work depicts the economical chillers sequencing of this hybrid chiller plant. Four different control sequence strategies are selected to perform numerical experiments of minimum operating costs are investigated based on the local electric and natural gas prices, for hotel building. The basis of these numerical experimental is listed in Section 3.

\subsection{Proposed Architecture Plan for Hotel Building}

In this current investigation, the numerical simulation procedure for air conditioning system focused on a model of a typical hotel building located on the Nile River in Cairo. This selected hotel building consists of 2 basements $(B 1+B 2)$, ground floor (G), 26 typical floors (from $1^{\text {st }}$ floor to $26^{\text {th }}$ floor), and the roof annex, as can be seen in Figure 1, for Sofitel Cairo Nile El-Gezirah Hotel. Each of the typical floors consists of 20 guest rooms (numbered by including the floor number). Figure 2 displays the architecture plan view for typical guest room typical floor from $1^{\text {st }}$ to $26^{\text {th }}$ level.

\subsection{Proposed Specifications for Hybrid Chiller Plant (HCP)}

In this current investigation, a model of hybrid chiller plant (HCP) for hotel building with 4000 refrigeration tonnage (TR) total cooling capacity $\left(\mathrm{Q}_{\mathrm{cc}}\right)$ is numerically simulated to perform the current numerical investigation. The proposed HCP consists of number $\left(\mathrm{N}_{\mathrm{ECH}}\right)$ of electric-driven centrifugal chiller(s) (ECHs) besides number $\left(\mathrm{N}_{\mathrm{GCH}}\right)$ of gas-driven absorption chiller(s) (GCHs). Table 1 summarizes the technical data and specifications of these chillers (ECHs,

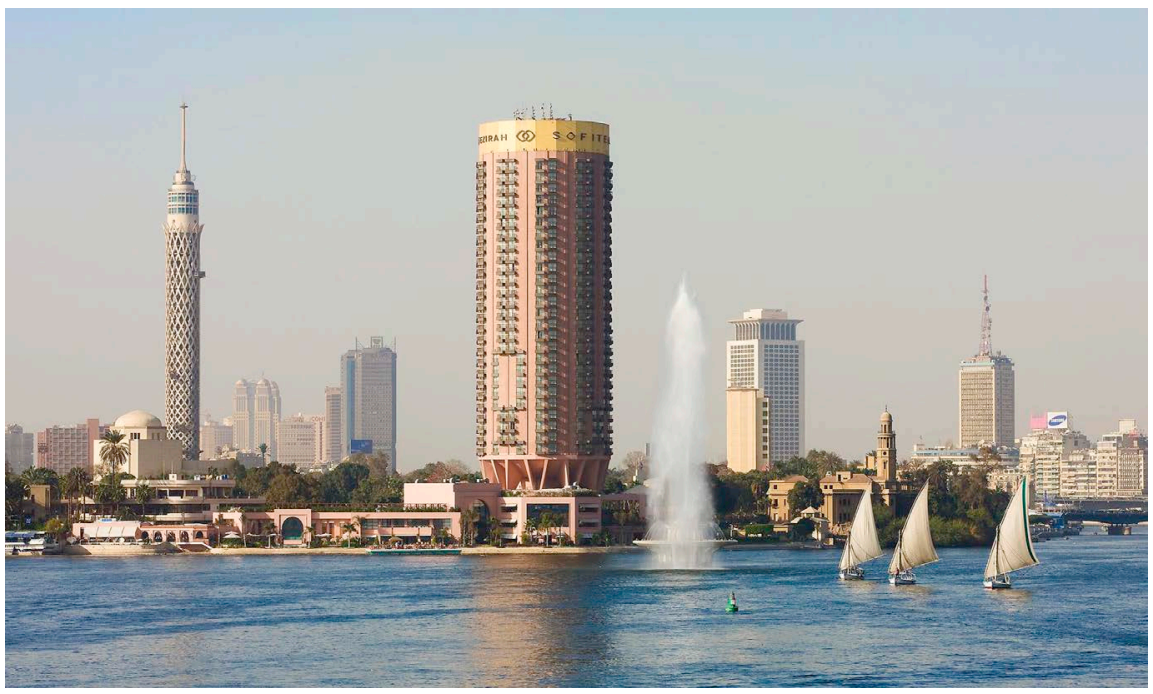

Figure 1. Hotel building on the Nile River. 


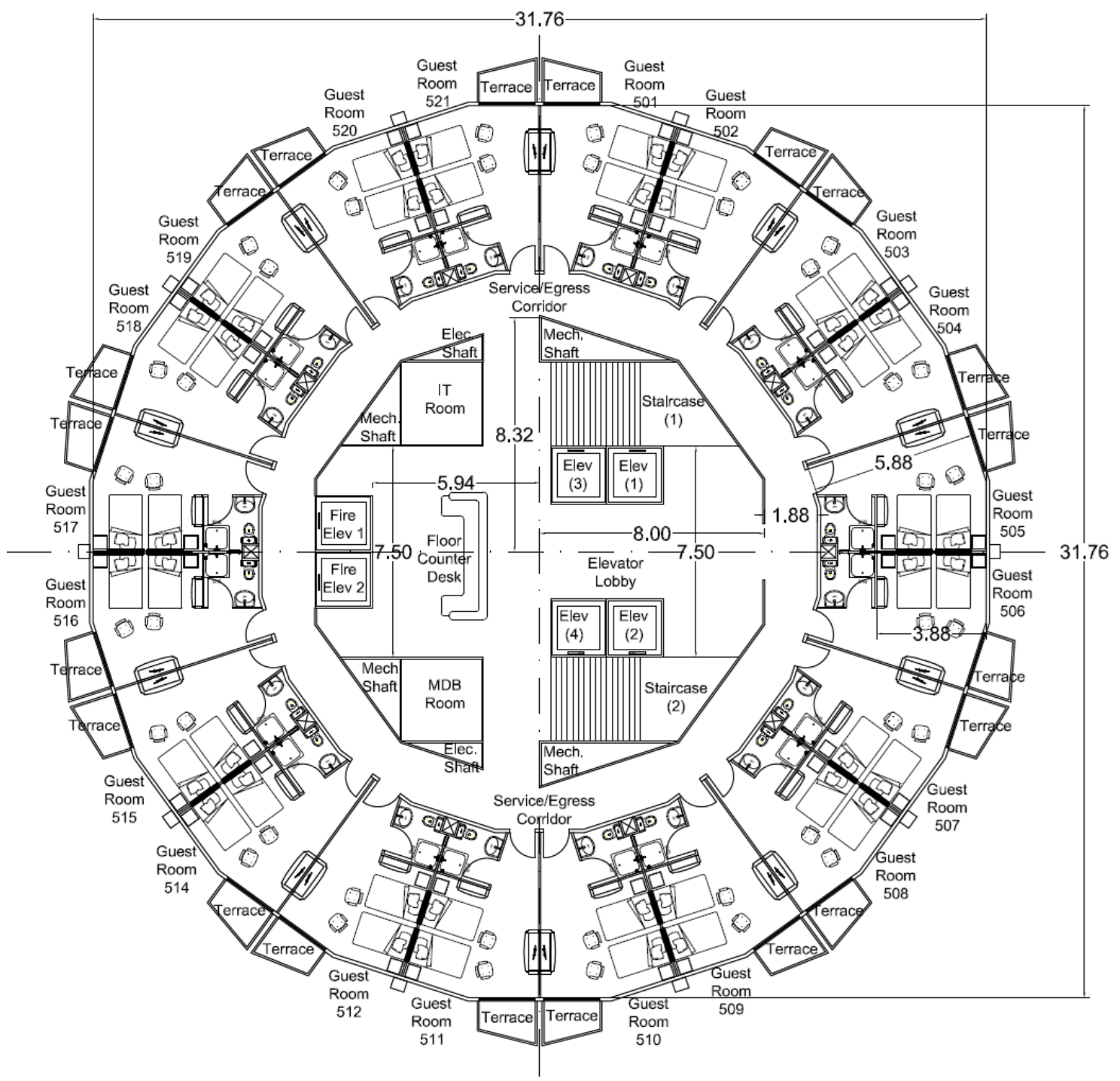

Figure 2. Architecture plan view for typical guest room typical floor from $1^{\text {st }}$ to $26^{\text {th }}$ level, shown on it all spaces names and dimensions.

and GCHs), which selected to build up the different design configurations (alternatives) of the investigated HCP of total cooling capacity of 4000 TR. In HCP, each chiller capacity is considered with 1000 TR per chiller. Table 1 gives the coefficient of performances, at full load and part load conditions, for these selected types of ECHs, and GCHs, and the electrical consumption, and gas consumption rates, and also the operating temperatures on both sides, evaporator side $\left(\mathrm{T}_{\text {evap }}\right)$ and condenser side $\left(\mathrm{T}_{\text {cond }}\right)$. Table 1 enumerates the chilled water temperatures ( $\mathrm{T}_{\text {chws }}$ and $\left.\mathrm{T}_{\text {chwr }}\right)$ and the cooling water temperatures $\left(\mathrm{T}_{\mathrm{cws}}\right.$ and $\left.\mathrm{T}_{\mathrm{cwr}}\right)$. A set of chilled water pumps (CHWPs) is used to circulate the chilled water within the HCP, and each of the served building, to provide the amount of chilled water to cooling coils inside the hotel building. On the other side, a set of cooling water pumps (CWPs) is used to provide the water cooled chillers, (ECHs and $\mathrm{GCHs}$ ), with the cooling water provided from the cooling towers (CTs). 
Table 1. Technical data and specifications for the electrical driven centrifugal chiller (ECH) and gas driven absorption chiller $(\mathrm{GCH})$.

\begin{tabular}{|c|c|c|c|}
\hline Comparison item & & $\begin{array}{l}\text { Electrical driven } \\
\text { centrifugal chiller } \\
(\mathrm{ECH})\end{array}$ & $\begin{array}{c}\text { Gas driven } \\
\text { absorption chiller } \\
(\mathrm{GCH})\end{array}$ \\
\hline - manufacturer & & York, USA [32] & Broad, China [33] \\
\hline \multicolumn{4}{|l|}{ - full load technical data } \\
\hline nominal cooling capacity, $\mathrm{Q}_{\mathrm{cc}}$ & TR & 1000 & 1000 \\
\hline compressor power, Pcomp. @ Full Load & $\mathrm{kW}$ & 600 & N/A \\
\hline solute pump power, $\mathrm{P}_{\text {pump }}$ & $\mathrm{kW}$ & N/A & 15 \\
\hline natural gas flow rate, $V_{{ } \mathrm{NG}}$ & $\mathrm{m}^{3} / \mathrm{hr}$ & N/A & 275 \\
\hline exergetic efficiency, $\eta_{\text {exergetic }}$ & $\%$ & 40 & 13 \\
\hline coefficient of performance, COP @ Full Load & & 5.6 & 1.3 \\
\hline coefficient of performance, COP @ Part Load & & $5.8-7$ & $1.0-1.2$ \\
\hline refrigerant type & & HFC-134a & $\mathrm{Li}-\mathrm{Br} / \mathrm{Water}$ \\
\hline \multicolumn{4}{|l|}{ - chilled water side } \\
\hline chilled water supply temperature, $\mathrm{T}_{\mathrm{CHws}}$ & ${ }^{\circ} \mathrm{C}$ & 7 & 7 \\
\hline chilled water return temperature, $\mathrm{T}_{\mathrm{CHWR}}$ & ${ }^{\circ} \mathrm{C}$ & 12 & 12 \\
\hline chilled water mass flow rate, $\mathrm{m}_{\text {chws }}$ & $\mathrm{kg} / \mathrm{s}$ & 150 & 150 \\
\hline evaporating temperature, $\mathrm{T}_{\text {evap }}$ & ${ }^{\circ} \mathrm{C}$ & -10 & 5 \\
\hline \multicolumn{4}{|l|}{ - cooling water side } \\
\hline cooling water supply temperature, $\mathrm{T}_{\mathrm{cws}}$ & ${ }^{\circ} \mathrm{C}$ & 30 & 30 \\
\hline cooling water return temperature, $\mathrm{T}_{\mathrm{CWR}}$ & ${ }^{\circ} \mathrm{C}$ & 35 & 35 \\
\hline cooling water mass flow rate, $\mathrm{m}_{\mathrm{cwr}}$ & $\mathrm{kg} / \mathrm{s}$ & 200 & 300 \\
\hline condensing temperature, $\mathrm{T}_{\text {cond }}$ & ${ }^{\circ} \mathrm{C}$ & 45 & 80 \\
\hline - part load control & & VSD & NGRV \\
\hline
\end{tabular}

\subsection{Basis of Energy and Water Consumptions}

The literature shows an economic analysis of a hybrid chiller plant consists of both electrical-driven centrifugal chillers and gas-driven absorption chillers. Natural gas was cheaper than electricity on a $(\$ / B t u)$. The price difference was not sufficient to offset the efficiency between electric and non-electric. This sub-section gives an overview of the basis of the energy prices which are used in this current numerical investigation of the proposed HCP for an administration building, and Hotel building, both of total cooling load of 4000 (TR). Table 2 
classifies initial costs $\left(I_{c}\right)$ in the local market for both selected typical models of chillers where each chiller with a maximum cooling capacity of $\mathrm{Q}_{c c}=1000$ (TR). Table 2 gives the running costs per each chiller (ECHs and GCHs) including electrical costs $\left(\mathrm{E}_{\mathrm{c}}\right)$, and natural gas costs $\left(\mathrm{G}_{\mathrm{c}}\right)$, to be used in the non-residential building, as per Egypt energy prices, in 2019/2020. Table 2 gives the energy prices using both currency rates for $\mathrm{E}_{\mathrm{c}}$ in (EGP/kWhr) and (USD/kWhr) and using both currency rates for $\mathrm{G}_{c}$ in $\left(\mathrm{EGP} / \mathrm{m}^{3} / \mathrm{hr}\right)$ and $\left(\mathrm{USD} / \mathrm{m}^{3} / \mathrm{hr}\right)$. The used currency transform rate is the currency rate in March 2021, which is around 15.75 (EGP) per 1 (USD). Figure 3 illustrates the proposed HCP, with design configuration II consists $\mathrm{N}_{\mathrm{ECH}}=2$ and $\mathrm{N}_{\mathrm{GCH}}=2$, with all the major system components required to fulfill the current numerical experiments on the proposed HCP.

Figure 3(a) illustrates the proposed HCP, with design configuration II consists $\mathrm{N}_{\mathrm{ECH}}=2$ and $\mathrm{N}_{\mathrm{GCH}}=2$, with all the major system components required to fulfill the current numerical experiments on the proposed HCP. Figure 3(b) illustrates the centrifugal chiller (by York) [32] screen displays a cutaway view of the chiller evaporator. All set points relating to the evaporator side of the chiller are maintained on this screen. Animation of the evaporation process indicates whether the chiller is presently in a RUN condition (bubbling) and liquid flow in the pipes is indicated by alternating shades of color moving in and out of the pipes. Figure 3(c) displays the absorption chiller (by Broad) [33] shown on it a cutaway view of the chiller evaporator, generator, condenser parameters such as temperature, water flow, gas flow, heat addition and heat rejection. All set points relating to the evaporator side of the chiller are maintained on this figure. The values shown in both Figure 3(b) and Figure 3(c) are in good agreement with those depicted in Table 1 for both types of chillers, either the electrical driven centrifugal chiller or the non-electrical absorption chiller.

Table 2. Prices data, initial costs $\left(\mathrm{I}_{\mathrm{c}}\right)$, electrical consumption cost $\left(\mathrm{E}_{\mathrm{c}}\right)$, gas consumption cost $\left(G_{c}\right)$, used for ECHs, and GCHs based on price lists of Egypt in 2019/2020.

\begin{tabular}{|c|c|c|c|}
\hline \multicolumn{2}{|l|}{ Comparison Item } & \multirow{2}{*}{$\begin{array}{c}\begin{array}{c}\text { Electrical Driven } \\
\text { Centrifugal Chiller } \\
\text { ECH-001 }\end{array} \\
\text { York, USA }\end{array}$} & \multirow{2}{*}{$\begin{array}{c}\text { Gas Driven } \\
\begin{array}{c}\text { Absorption Chiller } \\
\text { GCH-001 }\end{array} \\
\text { Broad, China }\end{array}$} \\
\hline - Manufacturer & & & \\
\hline - Nominal Cooling Capacity, $\mathrm{Q}_{\mathrm{cc}}$ & TR & 1000 & 1000 \\
\hline & USD/Chiller & 300,000 & 750,000 \\
\hline \multirow{2}{*}{ Initial cost, $I_{c}$} & EGP/Chiller & $4,950,000$ & $12,375,000$ \\
\hline & EGP/kWhr & 1.6 & N/A \\
\hline \multirow{2}{*}{ Electrical Cost, $\mathrm{E}_{\mathrm{c}}$} & USD/kWhr & 0.1 & N/A \\
\hline & EGP/kWhr & N/A & 2.75 \\
\hline Gas Cost, $\mathrm{G}_{\mathrm{c}}$ & USD/kWhr & N/A & 0.15 \\
\hline
\end{tabular}




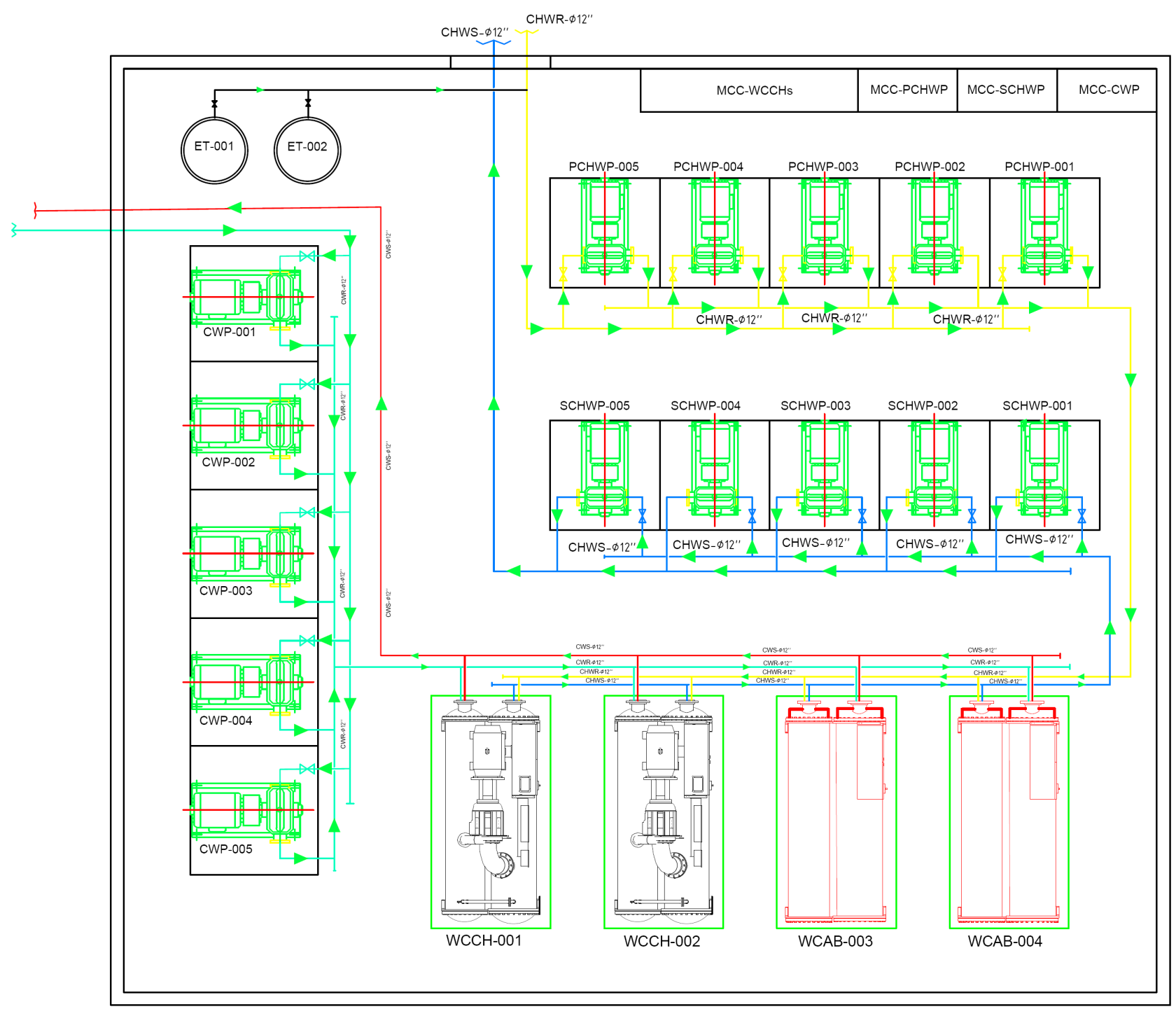

(a)

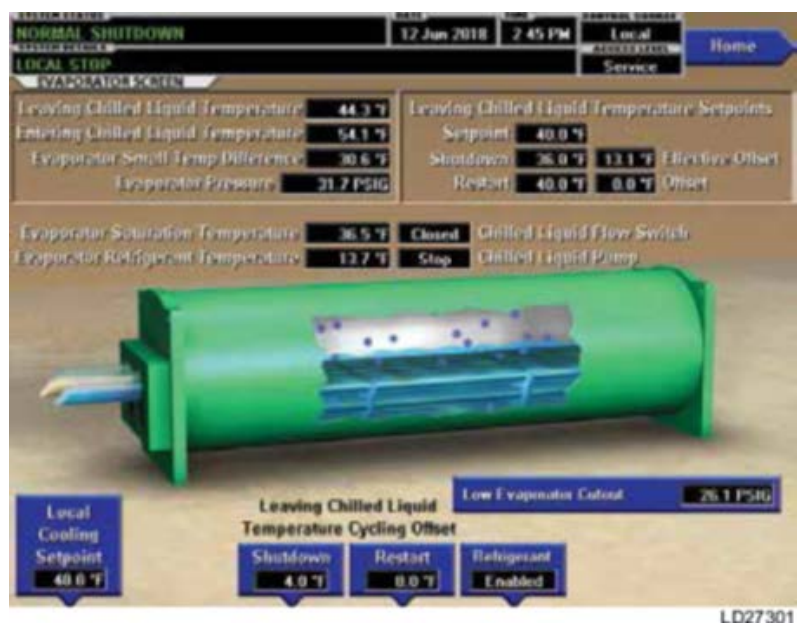

(a)

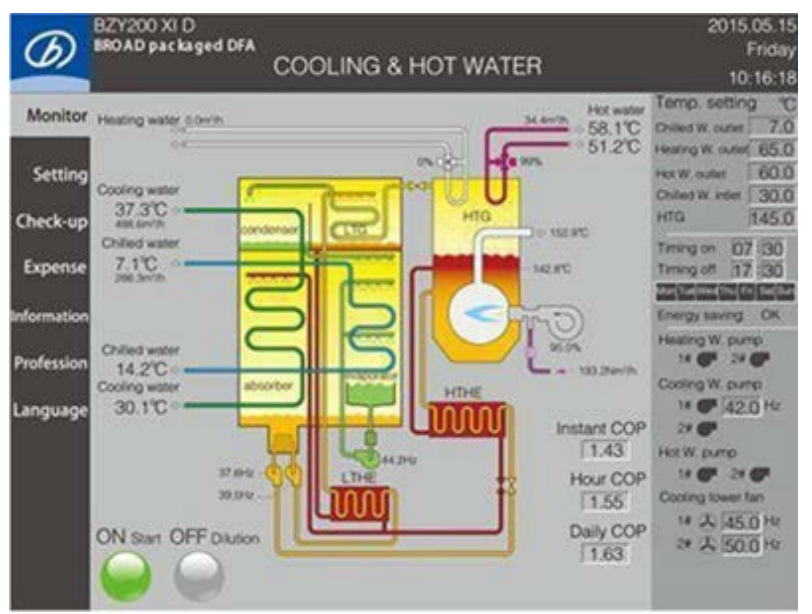

(b)

Figure 3. Details of HCP and chillers display screens. (a) Line diagram for proposed HCP, consists of $\mathrm{N}_{\mathrm{ECH}}=2$, and $\mathrm{N}_{\mathrm{GCH}}=2$, (b) Display screen for Centrifugal Chiller (by York) [32], and (c) Display screen for Absorption Chiller (by Broad) [33]. 
Figure 4 displays the cooling load profiles of the selected typical hotel building, which is plotted versus an hourly analysis basis. The cooling load profiles are depending on the cooling load components for each of the non-residential building load conditions. A typical cooling load presented in Figure 4 for a hotel building is with a maximum cooling load of 4000 (TR). Figure 4 depicts the corresponding running cost of two proposed traditional chiller plants, (non-hybrid chiller plants), where the first is driven with all electrical driven centrifugal chillers (ECHs), meanwhile the second is driven with all gas driven absorption chillers (GCHs). Those two configurations of chiller plants can be used during this current study, as two base cases for all the design configurations to proposed and investigated for the proposed HCP, to compare their results, referring to those two extreme cases of traditional chiller plant commonly used for the selected type of non-residential buildings. It should be clear from the preliminary results, shown in Figure 4, from the areas under both curves of $E_{c}$ and $\mathrm{G}_{\mathrm{c}}$ for both configurations of all ECHs, and all GCHs, that all GCHs configuration gives less total daily running costs than those of all ECHs configuration. This observation is clear and is due to the price basis of the used different kind of energy, as the price lists available considered in Egypt, as listed in Table 2. However, the $I_{c}$ impacts on the total cost of any traditional chiller plants have affected the decision-making process during the early design stages to design the chiller plant even to be using ECHs, or GCHs. It should be clear that the $I_{c}$ of GCH can reach about $250 \%$ of the $\mathrm{I}_{\mathrm{c}}$ of ECH, as stated by Smith [1] in his comparative study on hybrid chiller plant. Meanwhile this $I_{c}$ price ratio between $\mathrm{ECH}$ and $\mathrm{GCH}$ can be used in this article. Figure 5 displays summary of detailed

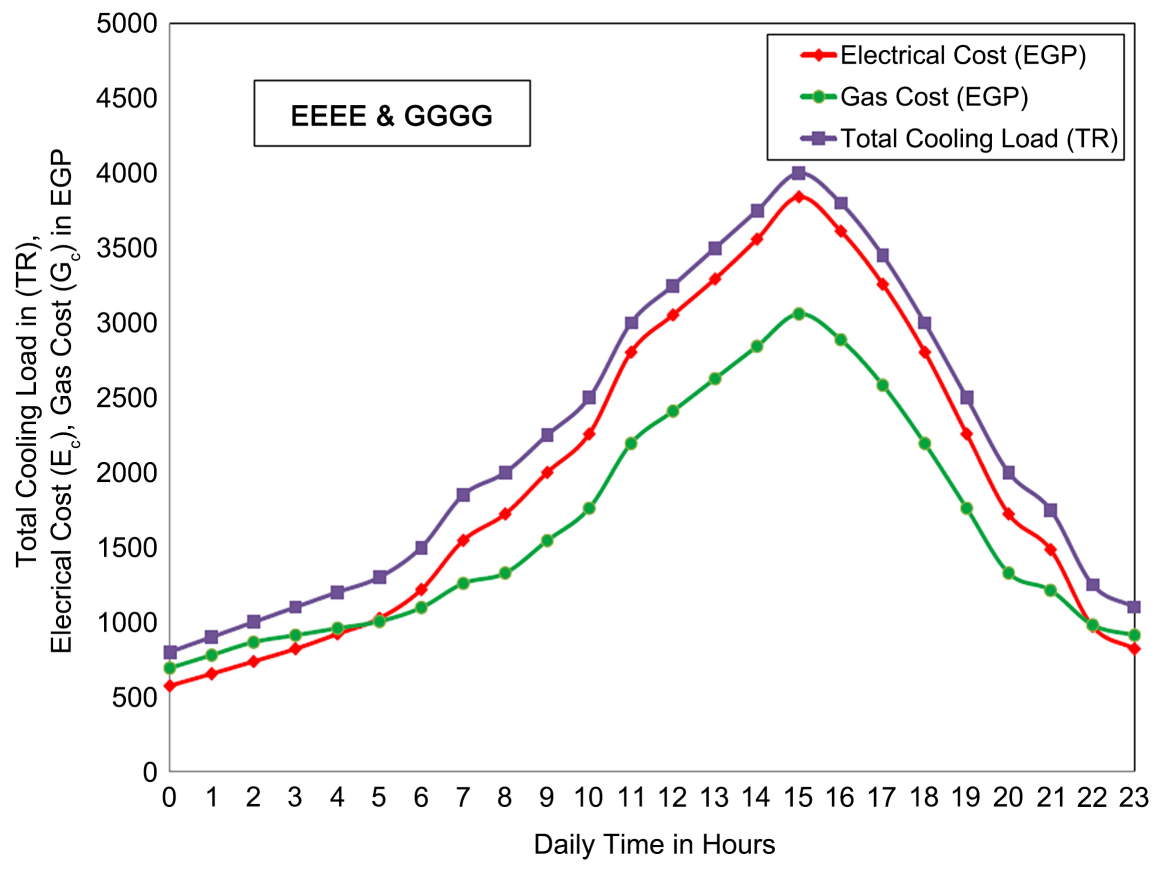

Figure 4. Cooling load ( $\mathrm{Q}_{\mathrm{cc}}$ ) profile for hotel building and the corresponding electrical cost $\left(E_{c}\right)$ for all ECHs plant (EEEE), and gas cost $\left(\mathrm{G}_{c}\right)$ for all $\mathrm{GCHs}$ plant (GGGG). 


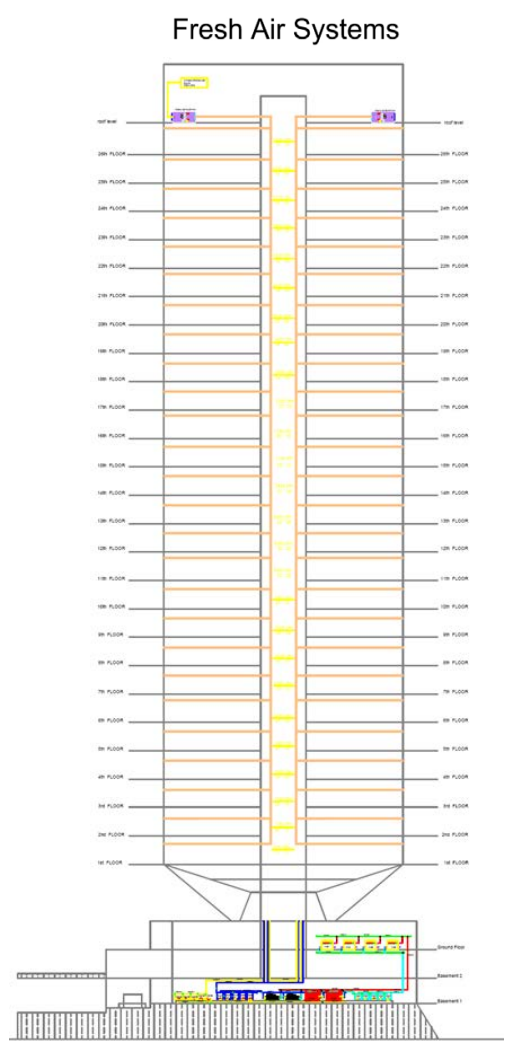

(a)

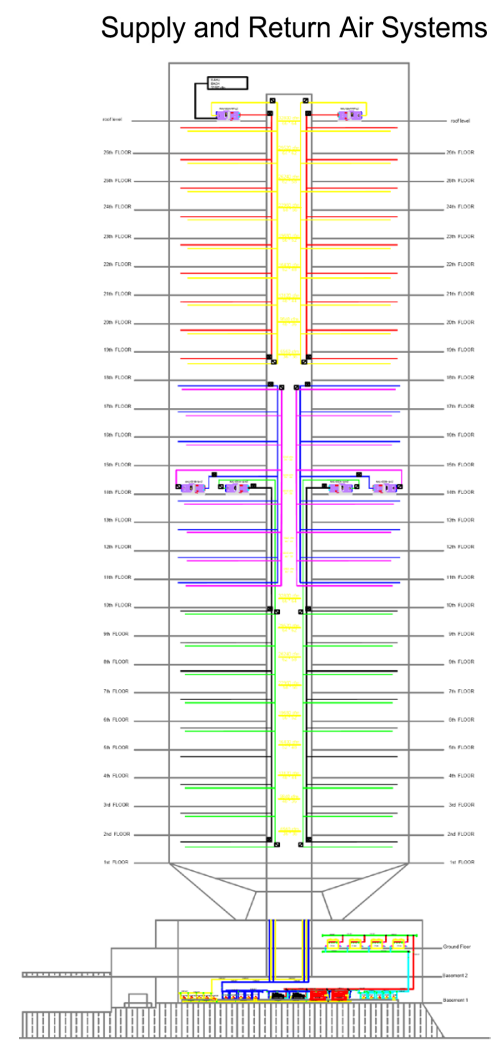

(b)

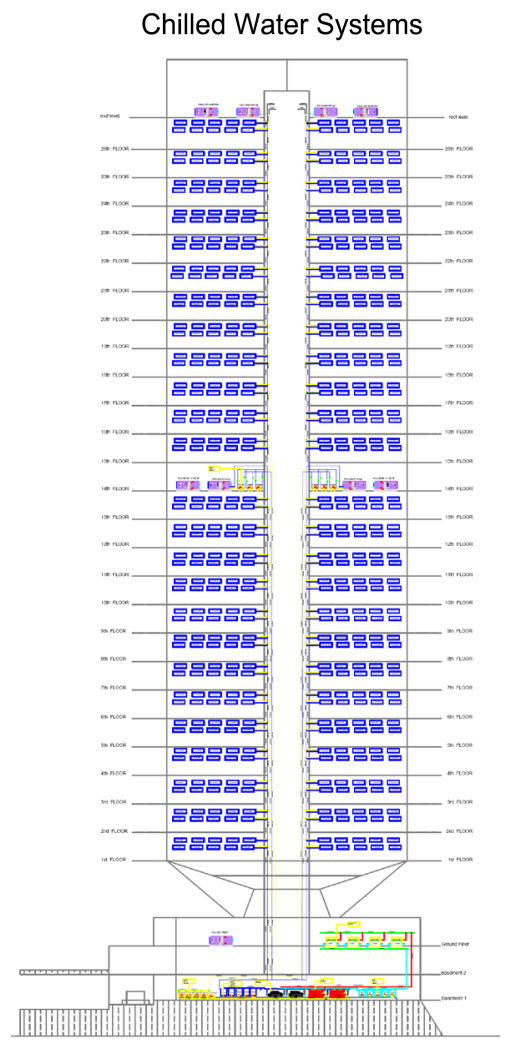

(c)

HVAC works for Typical Floor Plan

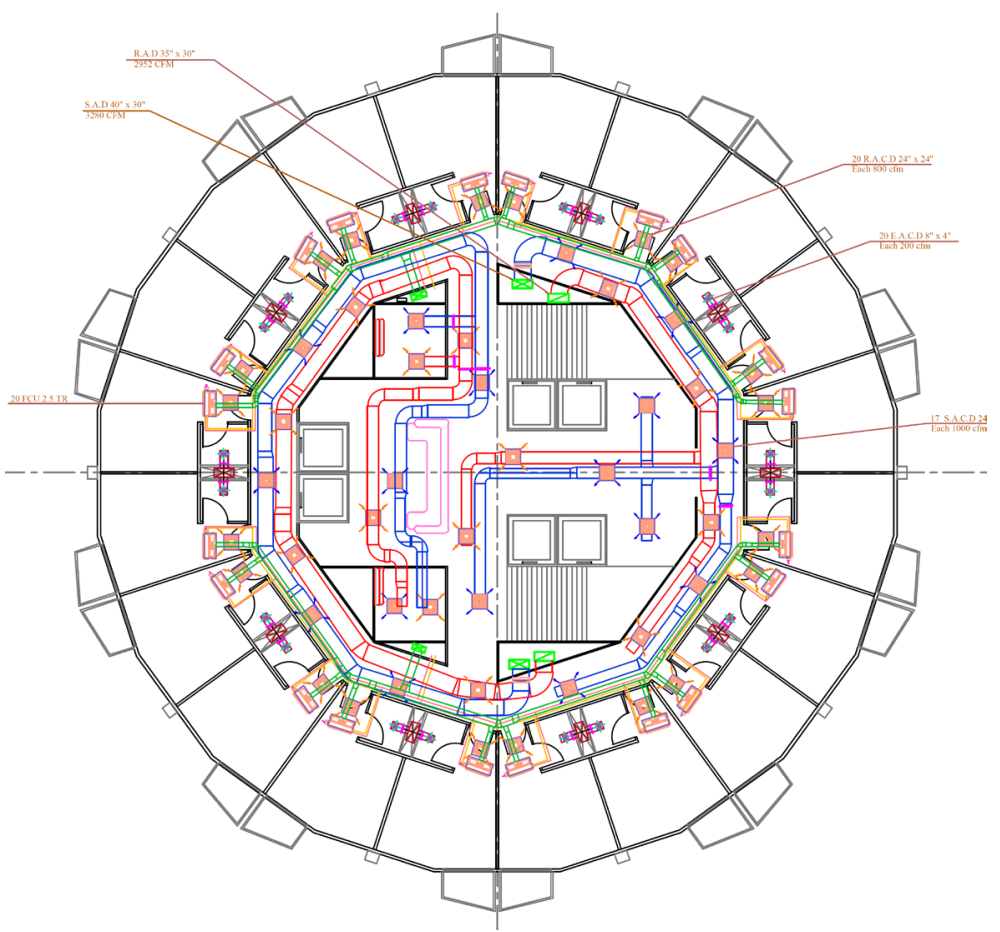

(d)

Figure 5. Details of air conditioning systems for hotel building typical floors from $1^{\text {st }}$ level to $26^{\text {th }}$ level demonstrated on both (a) Fresh air systems on riser diagram, (b) Supply and Return Air systems on riser diagram, (c) Chilled water systems on riser diagram, and (d) HVAC works for Typical Floor on typical floor plan. 
design of air conditioning systems for hotel building and its typical floor from $1^{\text {st }}$ level to $26^{\text {th }}$ level. Figure 5(a), Figure 5(b) demonstrates three or air side systems for air conditioning on building riser diagrams, which are 1) Fresh air ducting system required for supplying fresh air for air handling units and fan coil units inside guest room as can be seen in Figure 5(a), and 2) Supply and return air ducting systems which serve the public spaces inside hotel building floors as can be seen in Figure 5(b), respectively. Figure 5(c) displays the proposed chilled water on building riser diagram from HCP to all building cooling coils either for air handling units or for fan coil units. Also Figure 5(d) displays the proposed air systems and chilled water system on typical floor plan which is reparative typical floor from the hotel building $1^{\text {st }}$ floor to $26^{\text {th }}$ floor. It should be clear that Figure 5 depicts all the detailed design data about the proposed air conditioning system components inside the hotel building under consideration in the present study.

\section{Numerical Experiments}

This section includes the numerical experiments performed to simulate the energy consumptions for HCP using different design configurations (alternatives) based on the number of electrical-driven chillers $\mathrm{N}_{\mathrm{ECH}}$, and the number of gas-driven chillers $\mathrm{N}_{\mathrm{GCH}}$ inside the HCP under consideration. The operational sequencing strategies for the HCP are listed to investigate its effect on the cost minimization problem under-taken during this current study, as real-life case. Three configurations (Configuration I, Configuration II, Configuration III) of HCP are presented and compared in this study. The two traditional configurations of chiller plants of all electrically driven chillers ECHs (Configuration IV) and all gas driven chillers GCHs (Configuration V) are presented also to be considered as two extreme base cases to compare with their results. Besides, fourteen operational sequencing strategies are numerically investigated during the current decision-making process to detect the optimal design configuration and operational planning for the proposed HCP.

\subsection{Design Configuration and Operational Sequencing for HCP}

Table 3 depicts the design configurations for HCP configurations I, II, and III, in addition to the two base cases of traditional design configurations IV and V. In this table, the operational sequencing strategies (of 14 strategies) are grouped into two main groups based on the starting chiller which carrying the base load of the hotel building. As can be seen, configuration I consists of $\mathrm{N}_{\mathrm{ECH}}=3$ and $\mathrm{N}_{\mathrm{GCH}}=1$, configuration II consists of $\mathrm{N}_{\mathrm{ECH}}=2$ and $\mathrm{N}_{\mathrm{GCH}}=2$, and configuration III consists of $\mathrm{N}_{\mathrm{ECH}}=1$ and $\mathrm{N}_{\mathrm{GCH}}=3$. Meanwhile, the two base case configuration of all ECHs (configuration IV, with zero gas consumption) and of all GCHs (configuration $\mathrm{V}$, with almost zero electrical consumption) are also attached to the first line and the final line of Table 3 , to be used during the current comparative study, even for total running costs $\left(T_{c}\right)$ in EGP/day and also for their com- 
ponents, $\left(E_{c}\right)$ and $\left(G_{c}\right)$ in EGP/day for each of design configurations and their operational sequencing strategies, in addition to the initial cost $\left(\mathrm{I}_{\mathrm{c}}\right)$ in Millions of EGP for each of the proposed design options (configurations I, II, and III) for HCP compared with those traditional ones (configurations IV and V). Table 3 demonstrates the possible operational sequencing strategies for the four chiller loading sequence starting from carrying the baseload using the first chiller operation from the baseload (minimum load of the building during daily hours) up to $100 \mathrm{TR}$, meanwhile, the second and the third chillers are operated to carry out the loads from 1000 to 2000 TR, and from 2000 to 3000 TR, respectively. Finally, the fourth chiller is operated to fulfill the applied cooling loads from 3000 TR to $4000 \mathrm{TR}$, which the maximum expected cooling load of the hotel building, as can be seen in Figure 4.

Figure 6 illustrates loading sequencing for chillers in the HCP with selective operational strategy EEGG, which consists of first chiller is ECH-001, second chiller is ECH-002, third chiller is GCH-001, and fourth chiller is GCH-002, as depicted from Table 3. Figure 6 demonstrates the impact of this selective operational strategy on the profile of $\mathrm{E}_{\mathrm{c}}$ during working hours of ECHs (ECH-001 and ECH-002), and the impact it on the profile of $\mathrm{G}_{\mathrm{c}}$ during working hours of $\mathrm{GCHs}$

Table 3. Design configurations and operational sequencing strategies, using four chillers each of 1000 (TR) in HCP with total Qcc $=4000$ (TR) consists of $\mathrm{N}_{\mathrm{ECH}}$ and $\mathrm{N}_{\mathrm{GCH}}$.

\begin{tabular}{|c|c|c|c|c|c|c|c|c|c|c|c|c|c|}
\hline \multicolumn{2}{|c|}{$\begin{array}{c}\text { Design } \\
\text { Configuration }\end{array}$} & $\mathrm{N}_{\mathrm{ECH}}$ & $\mathrm{N}_{\mathrm{GCH}}$ & $\begin{array}{l}\text { Strategy } \\
\text { Code }\end{array}$ & $\begin{array}{c}1^{\text {st }} \\
\text { Chiller }\end{array}$ & $\begin{array}{c}2^{\text {nd }} \\
\text { Chiller }\end{array}$ & $\begin{array}{c}3^{\text {rd }} \\
\text { Chiller }\end{array}$ & $\begin{array}{c}4^{\text {th }} \\
\text { Chiller }\end{array}$ & $\begin{array}{c}\mathrm{E}_{\mathrm{C}} \\
\mathrm{EGP} / \text { day }\end{array}$ & $\begin{array}{c}\mathrm{G}_{\mathrm{C}} \\
\mathrm{EGP} / \text { day }\end{array}$ & $\begin{array}{c}\mathrm{T}_{\mathrm{C}} \\
\mathrm{EGP} / \text { day }\end{array}$ & $\begin{array}{c}\mathrm{I}_{\mathrm{C}} \\
\mathrm{EGP}\end{array}$ & $\mathrm{COP}_{\mathrm{HCP}}$ \\
\hline \multirow{8}{*}{ 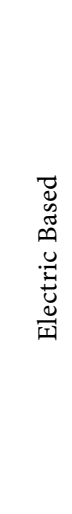 } & IV & 4 & 0 & EEEE & $\mathrm{ECH}-001$ & $\mathrm{ECH}-002$ & $\mathrm{ECH}-003$ & ECH-004 & 46,486 & N/A & 46,486 & $20 \mathrm{M}$ & 5.9 \\
\hline & I & 3 & 1 & EEEG & ECH-001 & $\mathrm{ECH}-002$ & $\mathrm{ECH}-003$ & GCH-001 & 43,302 & 2814 & 46,218 & $27 \mathrm{M}$ & 5.1 \\
\hline & I & 3 & 1 & EEGE & ECH-001 & $\mathrm{ECH}-002$ & GCH-001 & $\mathrm{ECH}-003$ & 7804 & 8011 & 45,816 & $27 \mathrm{M}$ & 5.04 \\
\hline & I & 3 & 1 & EGEE & ECH-001 & GCH-001 & ECH-002 & ECH-003 & 32,469 & 13,900 & 46,371 & $27 \mathrm{M}$ & 4.37 \\
\hline & II & 2 & 2 & EEGG & ECH-001 & $\mathrm{ECH}-002$ & GCH-001 & GCH-002 & 34,722 & 11,258 & 45,982 & $35 \mathrm{M}$ & 4.2 \\
\hline & II & 2 & 2 & EGEG & $\mathrm{ECH}-001$ & GCH-001 & ECH-002 & GCH-002 & 29,942 & 17,147 & 46,092 & $35 \mathrm{M}$ & 3.6 \\
\hline & II & 2 & 2 & EGGE & $\mathrm{ECH}-001$ & GCH-001 & GCH-002 & $\mathrm{ECH}-002$ & 23,583 & 23,860 & 47,444 & $35 \mathrm{M}$ & 3.53 \\
\hline & III & 1 & 3 & EGGG & ECH-001 & GCH-001 & GCH-002 & GCH-003 & 20,262 & 25,158 & 45,420 & $41 \mathrm{M}$ & 2.6 \\
\hline \multirow{8}{*}{$\begin{array}{l}\tilde{d} \\
\tilde{J} \\
\oplus \\
\tilde{J} \\
\tilde{J}\end{array}$} & III & 1 & 3 & GGGE & GCH-001 & GCH-002 & GCH-003 & ECH-001 & 3563 & 35,950 & 39,515 & $41 \mathrm{M}$ & 1.98 \\
\hline & III & 1 & 3 & GGEG & GCH-001 & GCH-002 & ECH-001 & GCH-003 & 8229 & 30,105 & 38,334 & $41 \mathrm{M}$ & 2.06 \\
\hline & III & 1 & 3 & GEGG & GCH-001 & ECH-001 & GCH-002 & GCH-003 & 14,460 & 30,269 & 44,730 & $41 \mathrm{M}$ & 2.74 \\
\hline & II & 2 & 2 & GGEE & GCH-001 & GCH-002 & ECH-001 & ECH-002 & 12,243 & 34,426 & 46,671 & $35 \mathrm{M}$ & 2.82 \\
\hline & II & 2 & 2 & GEGE & GCH-001 & ECH-001 & GCH-002 & $\mathrm{ECH}-002$ & 16,811 & 23,737 & 43,583 & $35 \mathrm{M}$ & 3.49 \\
\hline & II & 2 & 2 & GEEG & GCH-001 & $\mathrm{ECH}-001$ & $\mathrm{ECH}-002$ & GCH-002 & 23,140 & 23,773 & 40,585 & $35 \mathrm{M}$ & 3.57 \\
\hline & I & 3 & 1 & GEEE & GCH-001 & $\mathrm{ECH}-001$ & ECH-002 & $\mathrm{ECH}-003$ & 26,667 & 20,526 & 47,194 & $27 \mathrm{M}$ & 4.33 \\
\hline & V & 0 & 4 & GGGG & GCH-001 & GCH-002 & GCH-003 & GCH-004 & N/A & 39,199 & 39,199 & $50 \mathrm{M}$ & 1.23 \\
\hline
\end{tabular}




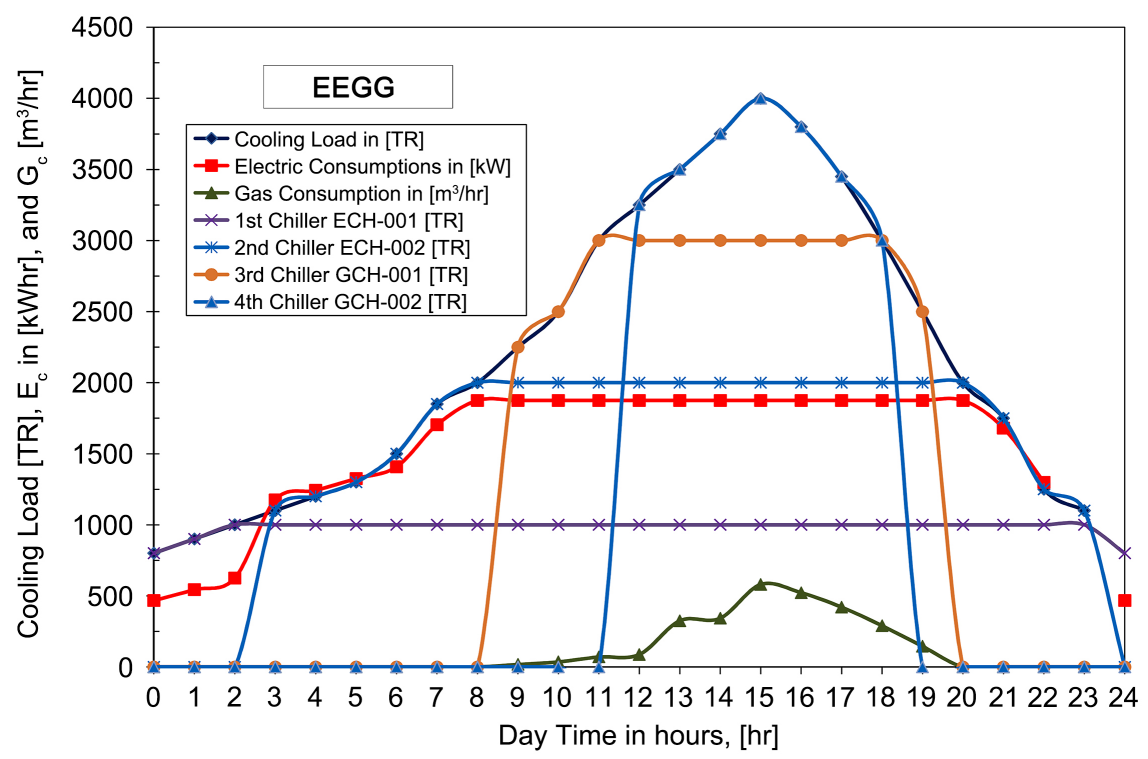

Figure 6. Hotel building cooling load profile $\left(\mathrm{Q}_{\mathrm{cc}}\right)$, electrical cost $\left(\mathrm{E}_{\mathrm{c}}\right)$, gas cost $\left(\mathrm{G}_{\mathrm{c}}\right)$, and chillers loading sequence (EEGG) for HCP.

(GCH-001 and GCH-002). Figure 6 demonstrates how the chiller sequencing in loading and unloading starts and ends, at the duration which does match with the proposed cooling load demand during 24 hours of typical summer day. It should be clear that for hotel building the base load is $800 \mathrm{TR}$ which is about $20 \%$ of the maximum cooling load of the building. Therefore, the first chiller is running for 24 hours continuously, and its minimum part load is about $80 \%$. However, the second and the third chillers are operated to carry out the loads from 1000 to $2000 \mathrm{TR}$, and from 2000 to $3000 \mathrm{TR}$, respectively, until the fourth chiller is operated to fulfill the applied cooling loads from 3000 TR to $4000 \mathrm{TR}$, (the maximum cooling load of Hotel building). As can be seen in Figure 6, electrical cost $\mathrm{E}_{\mathrm{c}}$ increases during loading hours starting for $\mathrm{t}=0$ am until the maximum value of $E_{c}$ at $t=8 \mathrm{am}$, and kept at this maximum value until $t=8 \mathrm{pm}$, then decreases to its minimum value again at $\mathrm{t}=0 \mathrm{am}$. On the other hand, the Gas cost, $\mathrm{G}_{\mathrm{c}}$ starts to increase from zero value (at $\mathrm{t}=9 \mathrm{am}$ ) to its maximum value (at $\mathrm{t}=3 \mathrm{pm}$ which corresponding to the maximum cooling load of the building), then it decreases to the zero value again (at $t=8 \mathrm{pm}$ ). It should be clear from Figure 6, that the shown loading sequence along the daily hours (from $t=0$ am up to $t=11: 59 \mathrm{am}$ ) is can be assumed for all the design configurations and for all the operational sequencing to carry out the full load profile for the hotel building.

\subsection{Initial and Running Costs for Hybrid Chiller Plant}

Figure 7 depicts the initial costs $\left(\mathrm{I}_{\mathrm{c}}\right)$ in million EGPs for design configurations from I to $\mathrm{V}$ (listed in Table 3 ) and the total running cost $\left(\mathrm{T}_{\mathrm{c}}\right)$ per summer day in thousands EGPs for different operating sequences. After assuming the cooling load profile for both of tested hotel building, presented in both Figure 4 and Figure 6. The total running cost $\left(\mathrm{T}_{\mathrm{c}}\right)$ per summer day estimated using the total 


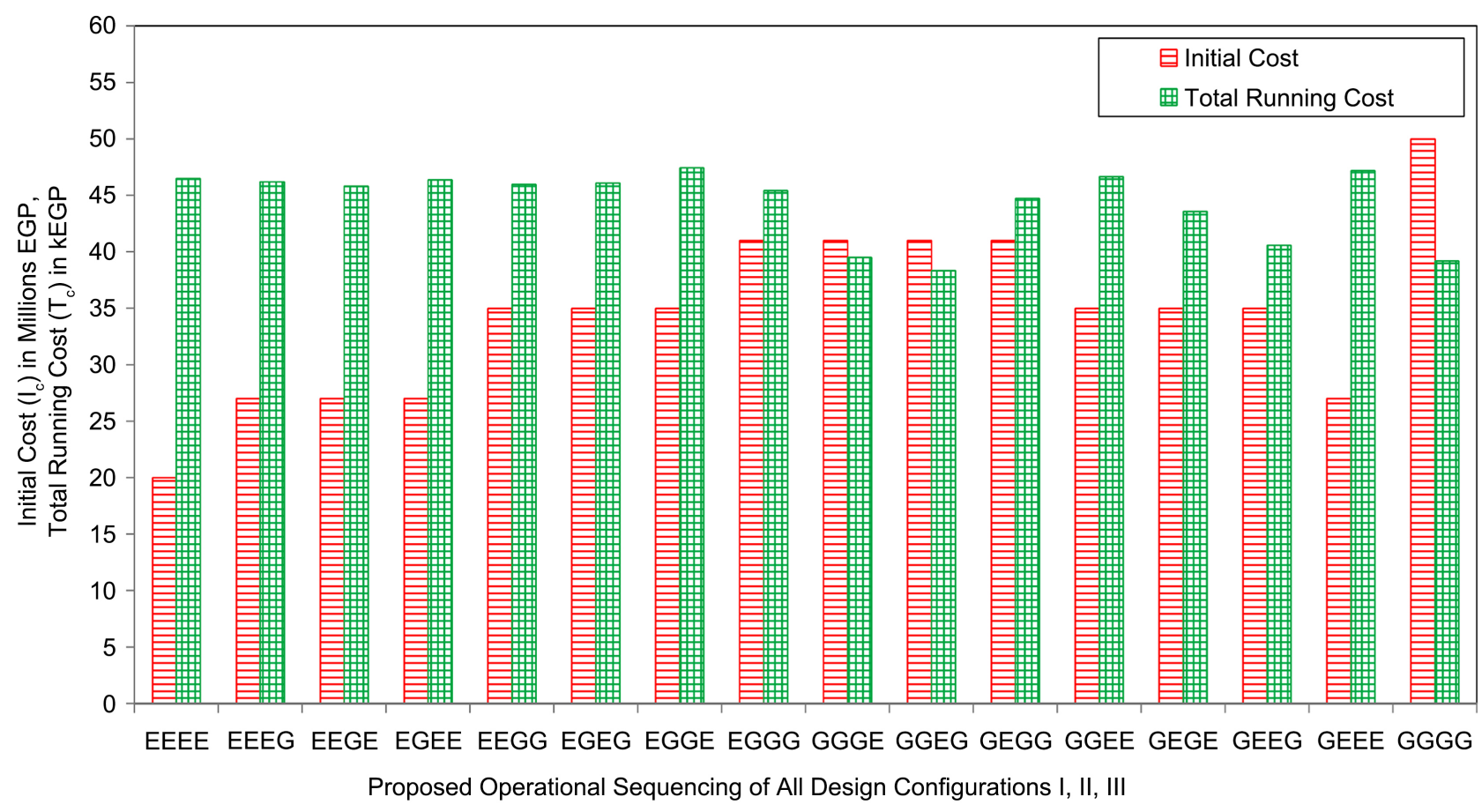

Figure 7. Operating cost components of electrical cost, gas cost, and total cost in EGPs for design options and all operational sequences.

summation running cost components $\mathrm{E}_{\mathrm{c}}, \mathrm{G}_{\mathrm{c}}$, and $\mathrm{W}_{\mathrm{c}}$ during all day hours for different design configurations I, II, III, IV and V, and under different operational strategies. Figure 6 shows that the minimum $I_{c}$ is observed for all electric chillers plant (configuration IV). However, the maximum $I_{c}$ is recorded for all gas chillers plant (configuration $\mathrm{V}$ ). On the other side, the values of initial costs $\mathrm{I}_{\mathrm{c}}$ for other design configurations from I, II, and III adverse from minimum value for configuration $\mathrm{I}\left(\mathrm{N}_{\mathrm{ECH}}=3\right.$ and $\left.\mathrm{N}_{\mathrm{GCH}}=1\right)$ to the maximum value for configuration III $\left(\mathrm{N}_{\mathrm{ECH}}=1\right.$ and $\left.\mathrm{N}_{\mathrm{GCH}}=3\right)$. These values are listed before in Table 3 . Figure 6 shows that $T_{c}$ per day fluctuates for different operating strategies of all design configurations from $I$ to $V$. However, the minimum $T_{c}$ is recorded for three operating strategies GGGG, GGGE, and GGEG. The maximum $T_{c}$ is observed for two operating strategies EGGE and GEEE. The discussion of these results are defined in next section 4 .

\subsection{Estimation of COPs for HCPs}

This subsection explores the methodology of estimating the apparent coefficient of performance of $\mathrm{HCP}\left(\mathrm{COP}_{\mathrm{HCP}}\right)$, as a function of each of the utilized four chillers, for design configurations I, II, and III, and under operational strategies. These estimated values can be used for the comparative study to select the optimal design options and operational strategies. Based on the energetic analysis, the COPHCP can be evaluated based on the experimentally measured parameters of both typical electrical chillers, and typical gas absorption chillers, available in the local market, and it can be expressed as can be seen in Equation (1). 


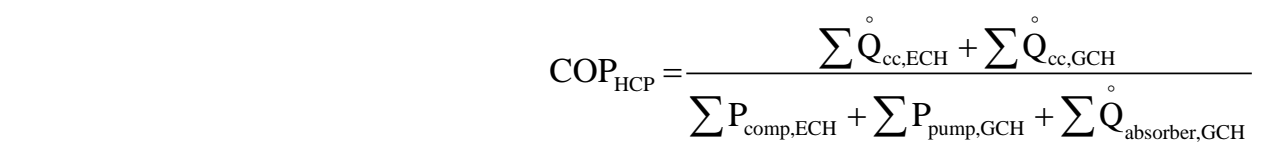

where $\mathrm{COP}_{\mathrm{HCP}}$ is the instantaneous coefficient of performance for $\mathrm{HCP}, \mathrm{Q}_{\mathrm{cc}, \mathrm{ECH}}$ and $\mathrm{Q}_{\mathrm{cc}, \mathrm{GCH}}$ are the cooling load generated by the electric-driven chiller and gas-driven chiller in (TR) respectively, $\mathrm{P}_{\text {comp, } \mathrm{ECH}}$ and $\mathrm{P}_{\text {pump,GCH }}$ are the consumed electrical power in $(\mathrm{kW})$ for compressors of electric-driven chillers and for the solute pump of gas-driven chiller respectively, and $\mathrm{Q}_{\text {absorber, } \mathrm{GCH}}$ is the thermal heat input required to the absorbers of gas driven chillers.

This apparent COP for HCP $\left(\mathrm{COP}_{\mathrm{HCP}, \text { app }}\right)$ is defined using the COPs of each chiller operating hours at full load conditions and part loading conditions also, and it can be expressed as can be seen in Equation (2).

$$
\mathrm{COP}_{\mathrm{HCP}, \text { app }}=\frac{\mathrm{COP}_{\mathrm{ECH}-001} \times \tau_{\mathrm{ECH}-001}+\mathrm{COP}_{\mathrm{ECH}-002} \times \tau_{\mathrm{ECH}-002}+\mathrm{COP}_{\mathrm{GCH}-001} \times \tau_{\mathrm{GCH}-001}+\mathrm{COP}_{\mathrm{GCH}-002} \times \tau_{\mathrm{GCH}-002}}{\tau_{\mathrm{ECH}-001}+\tau_{\mathrm{ECH}-002}+\tau_{\mathrm{GCH}-001}+\tau_{\mathrm{GCH}-002}}
$$

where $\mathrm{COP}_{\mathrm{HCP}, \text { app }}$ is the apparent coefficient of performance for HCP based on hourly analysis for the instantaneous values calculated from Equation (1), $\mathrm{COP}_{\mathrm{ECH}}$ and $\mathrm{COP}_{\mathrm{GCH}}$ are the coefficients of performance for both electrical driven chiller and gas driven chiller respectively, and $\tau_{\mathrm{ECH}}$ and $\tau_{\mathrm{GCH}}$ are the duty (operating hours percentage) for both electrical driven chiller and gas driven chiller respectively. The main source of these COP definitions expressed in both Equation (1) of power to power ration and Equation (2) of energy to energy ration is the conceptual definition of the COP for refrigeration machine which is defined as the total cooling load in $\mathrm{kW}$ or $\mathrm{kWhr}$ ) ref divided by the total power consumption for compressors for electrical centrifugal chillers or heat added as input as for non-electrical absorption chillers, in $\mathrm{kW}$ or total energy consumption in kWhr, respectively.

\subsection{Summary of the Cost Components and COP}

This subsection summarizes the numerically investigated data on HCP for hotel building for three design configurations I, II, and III, and under different operational strategies. Data reduction is used to group the numerically investigated data into two main groups to facilitate insight thermal performance and economic comparisons for the hybrid chiller plant with design configurations I, II, and III. Table 4 classifies four operational sequencing strategies of design configuration II $\left(\mathrm{N}_{\mathrm{ECH}}=2\right.$ and $\left.\mathrm{N}_{\mathrm{GCH}}=2\right)$. Table 4 gives that the $\mathrm{I}_{\mathrm{c}}$ is constant for the same design configuration II. Meanwhile, the minimum $\mathrm{T}_{\mathrm{c}}$ has recorded operating sequence GEGE, and the maximum $\mathrm{T}_{\mathrm{c}}$ has recorded operating sequence GGEE. On the other side, Table 4 gives that the apparent coefficient of performance for $\mathrm{HCP}\left(\mathrm{COP}_{\mathrm{HCP}, a p p}\right)$ decreases from its maximum value at 4.2 for EEGG, to its minimum value at 2.82 for GGEE. Table 5 compares four operational sequencing strategies, two from both design configurations $\mathrm{I}\left(\mathrm{N}_{\mathrm{ECH}}=3\right.$ and $\mathrm{N}_{\mathrm{GCH}}=$ 1), and III $\left(\mathrm{N}_{\mathrm{ECH}}=1\right.$ and $\left.\mathrm{N}_{\mathrm{GCH}}=3\right)$. Table 5 shows that the $\mathrm{I}_{\mathrm{c}}$ are different for each design configuration I and III, such its minimum value records 27 million 
Table 4. Four operational sequencing strategies of design configuration $\mathrm{II}\left(\mathrm{N}_{\mathrm{ECH}}=2\right.$ and $\left.\mathrm{N}_{\mathrm{GCH}}=2\right)$.

\begin{tabular}{|c|c|c|c|c|c|c|c|c|}
\hline $\begin{array}{c}\text { Design } \\
\text { Configuration }\end{array}$ & $\mathrm{N}_{\mathrm{ECH}}$ & $\mathrm{N}_{\mathrm{GCH}}$ & $\begin{array}{l}\text { Strategy } \\
\text { Code }\end{array}$ & $\begin{array}{c}\mathrm{E}_{\mathrm{c}} \\
\mathrm{EGP} / \text { day }\end{array}$ & $\begin{array}{c}\mathrm{G}_{\mathrm{c}} \\
\text { EGP/day }\end{array}$ & $\begin{array}{c}\mathrm{T}_{\mathrm{c}} \\
\text { EGP/day }\end{array}$ & $\begin{array}{c}\mathrm{I}_{\mathrm{c}} \\
\mathrm{EGP}\end{array}$ & $\mathrm{COP}_{\mathrm{HCP}}$ \\
\hline II & 2 & 2 & EEGG & 34,722 & 11,258 & 45,982 & $35 \mathrm{M}$ & 4.2 \\
\hline II & 2 & 2 & EGEG & 29,942 & 17,147 & 46,092 & $35 \mathrm{M}$ & 3.6 \\
\hline II & 2 & 2 & GEGE & 16,811 & 23,737 & 43,583 & $35 \mathrm{M}$ & 3.49 \\
\hline II & 2 & 2 & GGEE & 12,243 & 34,426 & 46,671 & $35 \mathrm{M}$ & 2.82 \\
\hline
\end{tabular}

Table 5. Four operational sequencing strategies of design configuration $\mathrm{I}\left(\mathrm{N}_{\mathrm{ECH}}=3\right.$ and $\left.\mathrm{N}_{\mathrm{GCH}}=1\right)$ and design configuration III $\left(\mathrm{N}_{\mathrm{ECH}}=1\right.$ and $\left.\mathrm{N}_{\mathrm{GCH}}=3\right)$.

\begin{tabular}{|c|c|c|c|c|c|c|c|c|}
\hline $\begin{array}{c}\text { Design } \\
\text { Configuration }\end{array}$ & $\mathrm{N}_{\mathrm{ECH}}$ & $\mathrm{N}_{\mathrm{GCH}}$ & $\begin{array}{c}\text { Strategy } \\
\text { Code }\end{array}$ & $\begin{array}{c}\mathrm{E}_{\mathrm{c}} \\
\mathrm{EGP} / \text { day }\end{array}$ & $\begin{array}{c}\mathrm{G}_{\mathrm{c}} \\
\mathrm{EGP} / \text { day }\end{array}$ & $\begin{array}{c}\mathrm{T}_{\mathrm{c}} \\
\text { EGP/day }\end{array}$ & $\begin{array}{c}\mathrm{I}_{\mathrm{c}} \\
\mathrm{EGP}\end{array}$ & $\mathrm{COP}_{\mathrm{HCP}}$ \\
\hline I & 3 & 1 & EEEG & 43,302 & 2814 & 46,218 & $27 \mathrm{M}$ & 5.1 \\
\hline I & 3 & 1 & GEEE & 26,667 & 20,526 & 47,194 & $27 \mathrm{M}$ & 4.33 \\
\hline III & 1 & 3 & EGGG & 20,262 & 25,158 & 45,420 & $41 \mathrm{M}$ & 2.6 \\
\hline III & 1 & 3 & GGGE & 3563 & 35,950 & 39,515 & $41 \mathrm{M}$ & 1.98 \\
\hline
\end{tabular}

EGPs for configuration I, however, its maximum value records 41 million EGPs for configuration III. Meanwhile, the minimum $T_{c}$ has recorded operating sequence GGGE of configuration III, and the maximum $T_{c}$ has recorded operating sequence GEEE of configuration I. On the other side, Table 5 depicts that the apparent coefficient of performance for HCP $\left(\mathrm{COP}_{\mathrm{HCP}, \mathrm{app}}\right)$ decreases from its maximum value at 5.1 for EEEG, to its minimum value at 1.98 for GGGE.

\section{Results and Discussion}

This section demonstrates the results of numerical experiments performed to investigate both economic studies by estimating $\mathrm{E}_{\mathfrak{c}}, \mathrm{G}_{\mathfrak{c}}, \mathrm{W}_{\mathfrak{c}}$, and $\mathrm{T}_{\mathfrak{c}}$, and thermal performance study by evaluating $\mathrm{COP}_{\mathrm{HCP}, \mathrm{app}}$, for all design configurations and operating sequences. The results of cost components $\left(\mathrm{E}_{c}, \mathrm{G}_{\mathfrak{c}}, \mathrm{W}_{c}\right.$, and $\left.\mathrm{T}_{\mathrm{c}}\right)$ and $\mathrm{COP}_{\mathrm{HCP}, \text { app }}$ for $\mathrm{HCP}$ with different designs and operating sequences are presented in subsections 4.1,4.2, respectively. The effects of both design configurations and operating sequences on the two important axes in the current comparative study which are depending on economical evaluation and thermal performance studies are discussed in subsection 4.3 and 4.4 , respectively.

\subsection{Results of Cost Components for HCP with Different Designs and Operating Sequences}

Figure 8 displays $E_{c}, G_{c}, W_{c}$, and $T_{c}$ for hotel building with design configuration II under different operational strategies (a) EEGG, (b) EGEG, (c) GEGE, and (d) GGEE. Similarly, Figure 9 depicts $E_{c}, G_{c}, W_{c}$, and $T_{c}$ for design configuration $I$ under different operational strategies (a) EEEG, and (b) GEEE, and for design 


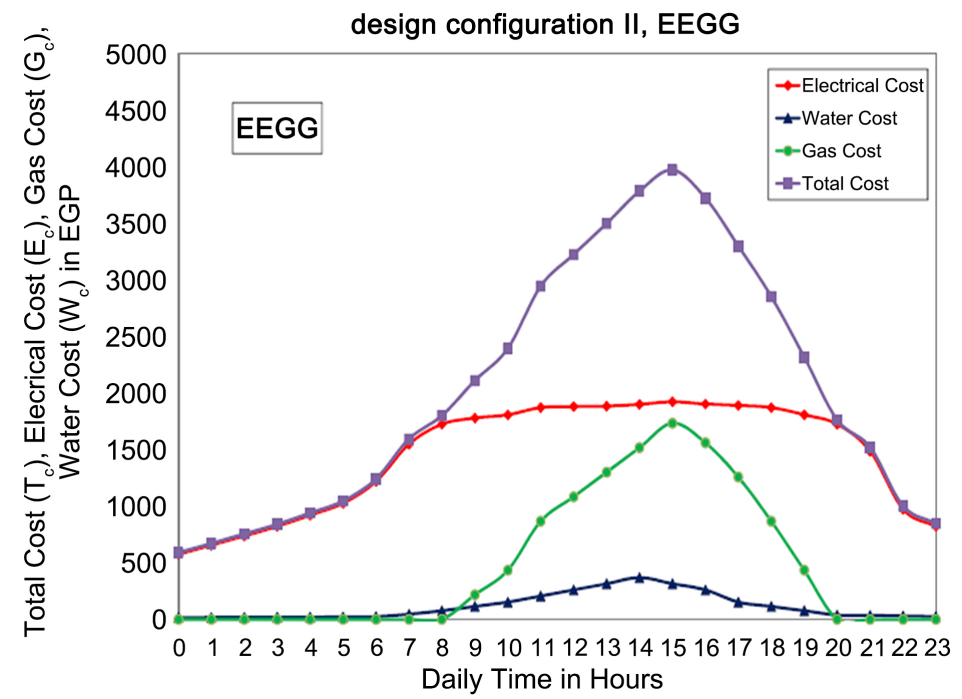

(a)

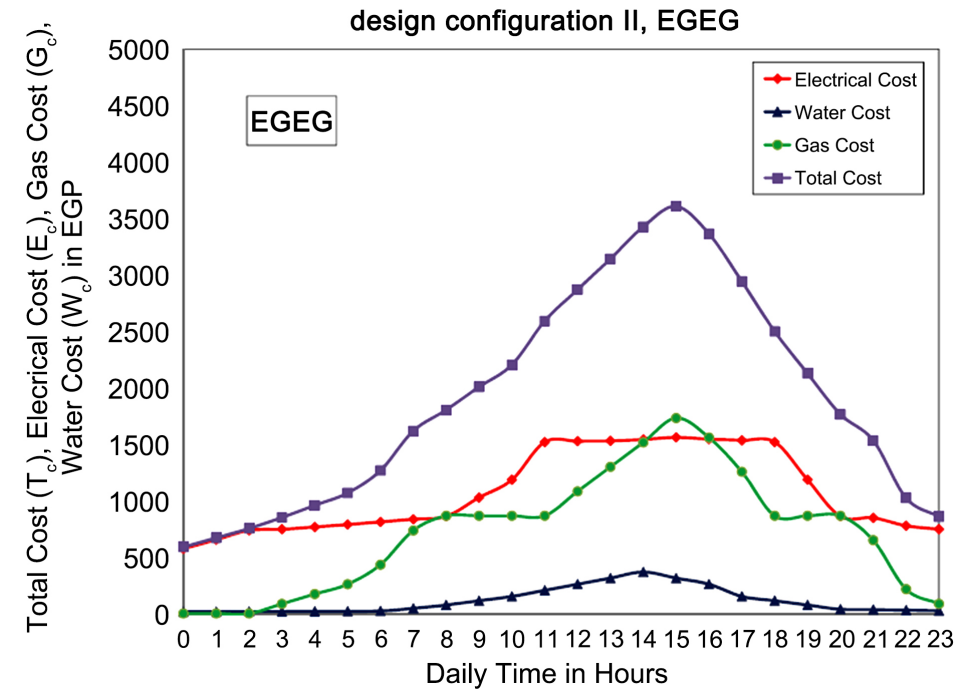

(b)

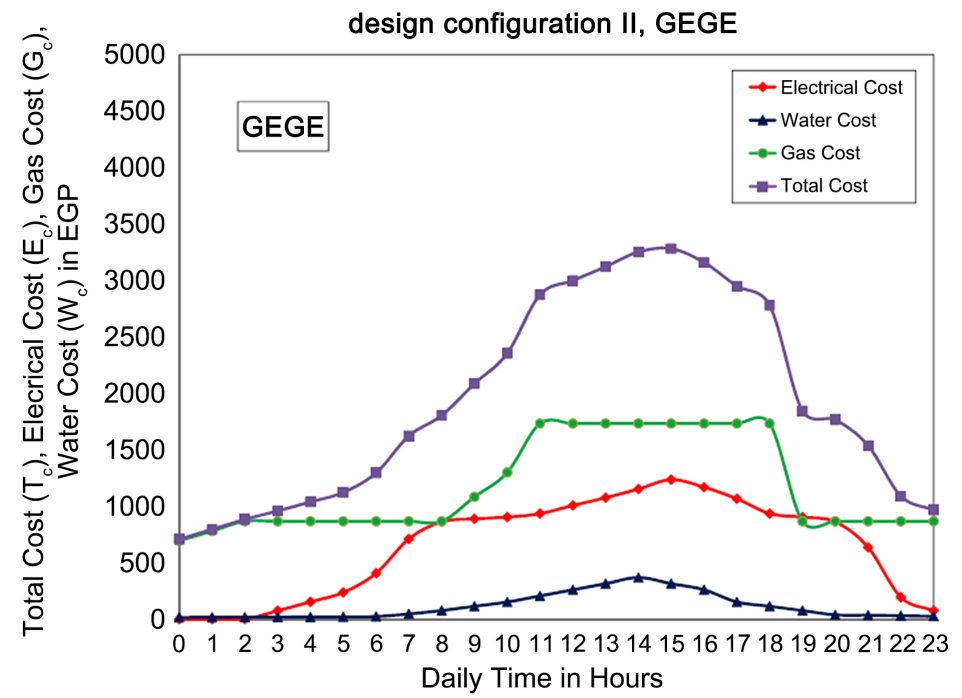

(c) 


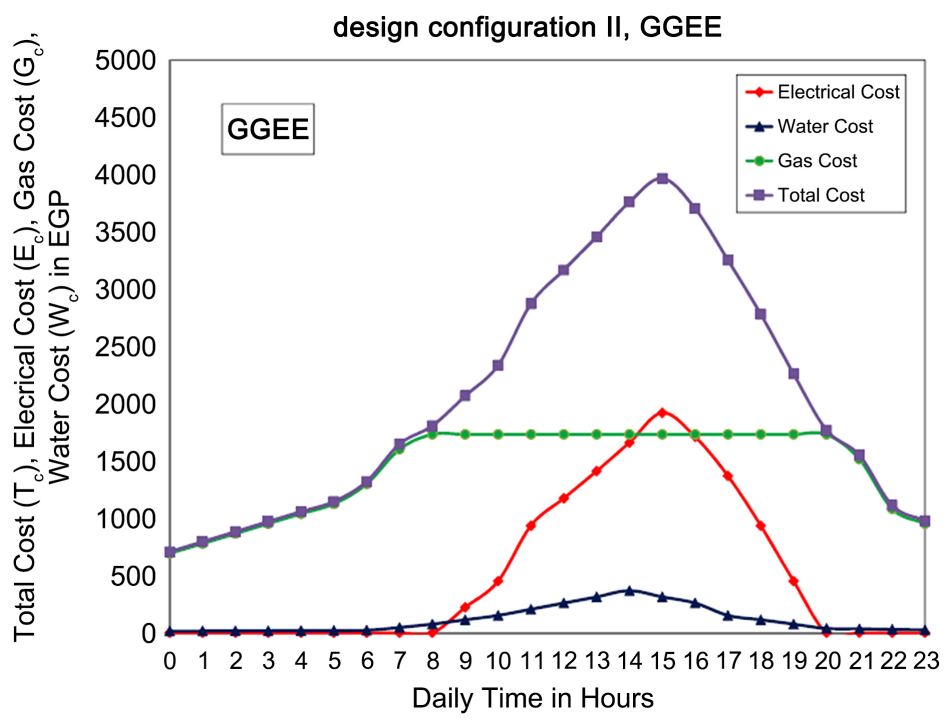

(d)

Figure 8. Electrical cost $\left(E_{c}\right)$, gas cost $\left(G_{c}\right)$, water cost $\left(W_{c}\right)$ and total Cost $\left(T_{c}\right)$ for design configuration II under different operational strategies (a) EEGG, (b) EGEG, (c) GEGE, and (d) GGEE.

configuration III (c) EGGG, and (d) GGGE. The comparison between different design configuration I, II, and III and under different operational strategies can be made based on the results depicted from both Figure 8 and Figure 9. Figure 8 and Figure 9 demonstrate the impact of different design configurations and operational sequences of HCP to carry out the cooling load profiles of the hotel building, on the running costs of designed HCP, and their cost components of $E_{c}, G_{c}, W_{c}$, and $T_{c}$. Figure 8(a) and Figure 8(b) illustrate that for both EEGG and EGEG respectively, the areas under the $\mathrm{E}_{\mathrm{c}}$ curves are larger than those areas under $\mathrm{G}_{\mathrm{c}}$. This observation reveals that EEGG and EGEG consumed electrical power costs higher than those gas consumption costs. However, Figure $8(\mathrm{c})$ and Figure 8(d) display that for both GEGE and GGEE respectively, the areas under the $E_{c}$ curves are smaller than those areas under $G_{c}$. This observation reveals that GEGE and GGEE consumed electrical power costs lower than those gas consumption costs. Figures 8(a)-(d) show that the maximum $T_{c}$ is recorded for EEGG (Figure 8(a)), and GGEE (Figure 8(d)), meanwhile the minimum $T_{c}$ is recorded for GEGE (Figure 8(c)). All Figures 8(a)-(d) show that $W_{c}$ has no significant effects on $T_{c}$ for all operating sequences under consideration in design configuration II, presented in Figure 8. Similarly, Figure 9(a) and Figure 9(b) illustrate that both EEEG and GEEE respectively, the areas under the $\mathrm{E}_{\mathrm{c}}$ curves are larger than those areas under $\mathrm{G}_{c}$. This observation reveals that EEEG and GEEE consumed electrical power costs higher than those gas consumption costs. However, Figure 9(c) and Figure 9(d) display that for both EGGG and GGGE respectively, the areas under the $\mathrm{E}_{\mathrm{c}}$ curves are smaller than those areas under $G_{c}$. This observation reveals that GEGE and GGEE consumed electrical power costs lower than those gas consumption costs. Figures 9(a)-(d) show that 


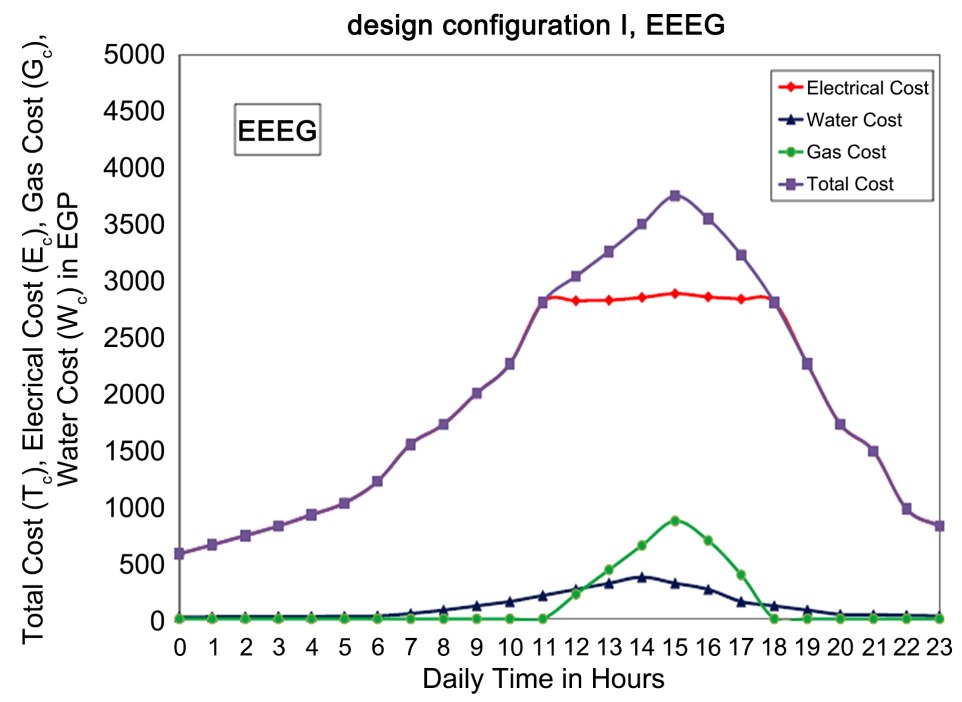

(a)

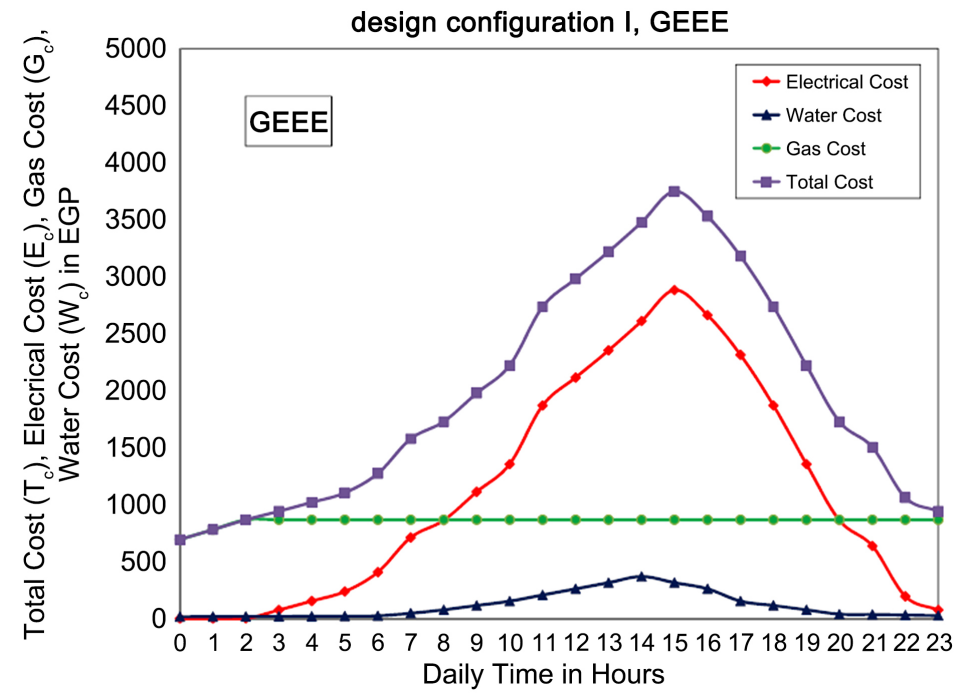

(b)

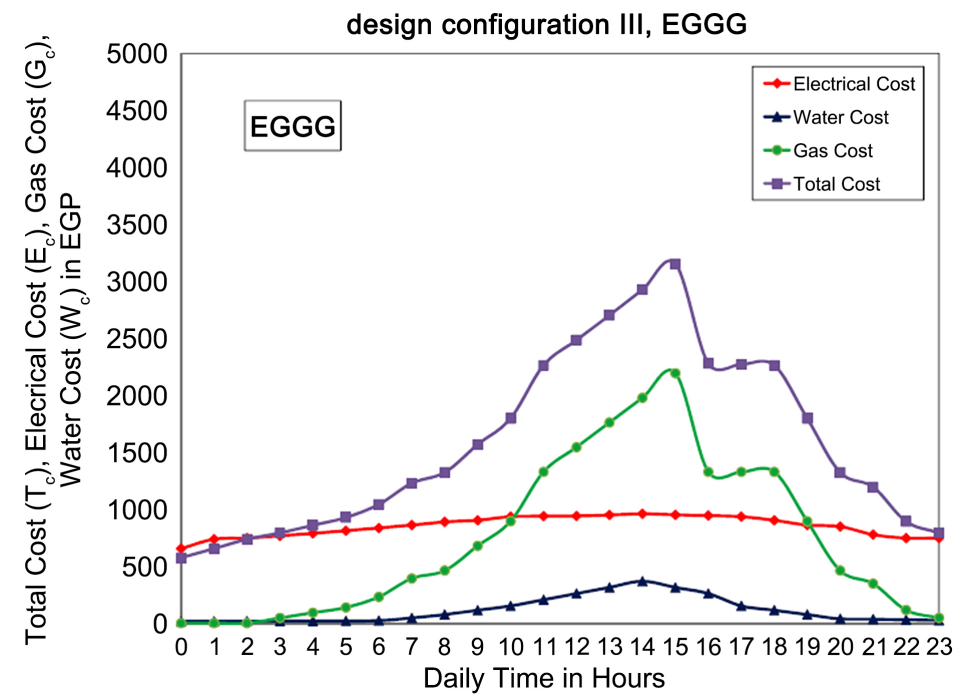

(c) 


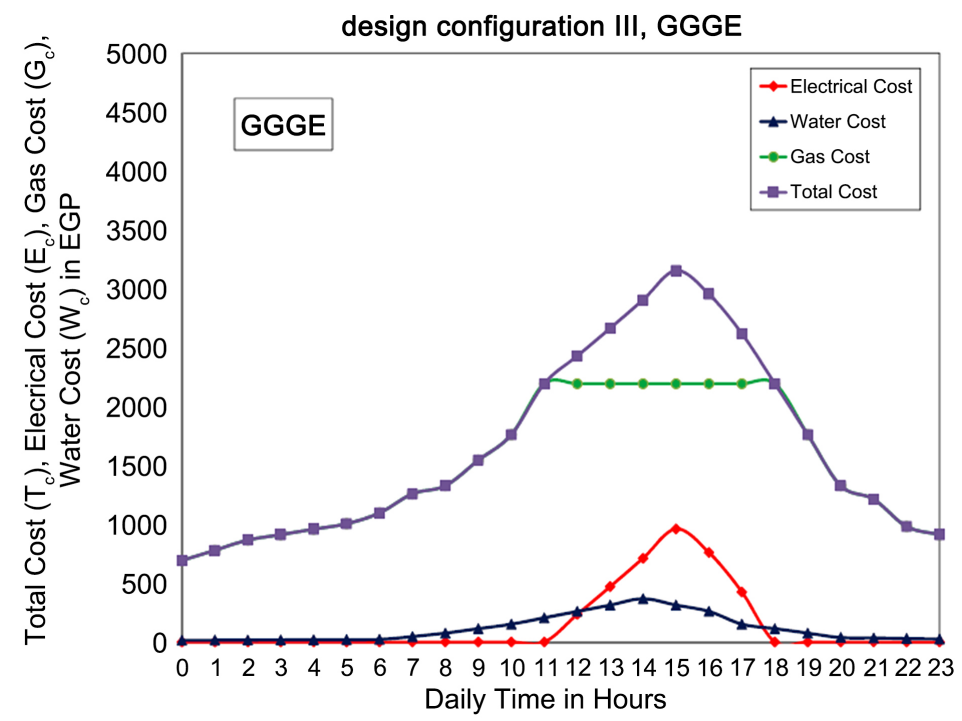

(d)

Figure 9. Electrical cost $\left(\mathrm{E}_{c}\right)$, gas cost $\left(\mathrm{G}_{c}\right)$, water cost $\left(\mathrm{W}_{c}\right)$ and total cost $\left(\mathrm{T}_{c}\right)$ for design configurations I, and III under different operational strategies (a) EEEG, (b) GEEE, (c) EGGG, and (d) GGGE.

the maximum $T_{c}$ is recorded for both EEEG (Figure 9(a)), and GEEE (Figure 9(b)), meanwhile, the minimum $T_{c}$ has recorded for both EGGG (Figure 9(c)) and GGGE (Figure 9(d)). All Figures 9(a)-(d) confirm that $\mathrm{W}_{\mathrm{c}}$ has no significant effects on $T_{c}$ for all operating sequences under consideration in design configurations I, and III, presented in Figure 9.

Figure 10(a), Figure 10(b), and Figure 10(c) demonstrate the operational cost components of electrical cost $E_{c}$, gas cost $G_{c}$, and total cost Tc in EGPs in three groups of design options 1$)$ configuration $\mathrm{I}\left(\mathrm{N}_{\mathrm{ECH}}=3\right.$ and $\left.\left.\mathrm{N}_{\mathrm{GCH}}=1\right), 2\right)$ configuration II ( $\mathrm{N}_{\mathrm{ECH}}=2$ and $\left.\mathrm{N}_{\mathrm{GCH}}=2\right)$, and 3) configuration III $\left(\mathrm{N}_{\mathrm{ECH}}=1\right.$ and $\mathrm{N}_{\mathrm{GCH}}=3$ ). The results of Figure 10(a) for configuration I reveal that the minimum values for $E_{c}, G_{c}$, and $T_{c}$ are observed for GEEE, EEEG, and EEGE, respectively. However, the results of Figure 10(b) for configuration II reveal that the minimum values for $E_{c}, G_{c}$, and $T_{c}$ are observed for GGEE, EEGG, and GEEG, respectively. On the other side, the results depicted in Figure 10(c) for configuration III reveal that the minimum values for $E_{c}, G_{c}$, and $T_{c}$ are observed for GGGE, EGGG, and GGEG, respectively. Figure 11 displays the operational cost components of electrical cost $E_{c}$, gas cost $G_{c}$, and total cost $T_{c}$ in EGPs for all design options and all operational sequences. Figure 11 summarizes the results of operational running cost components and total running cost also. The results of Figure 11 for all design options and all operational sequences reveal that the minimum values for $E_{c}, G_{c}$, and $T_{c}$ are observed for GGGE, EEEG, and GGEG, respectively. Figure 11 is a helpful tool for both the building cooling systems designers and the building operators to select the optimal design and optimal operating sequences by minimizing the value of either any of the operating cost components $\mathrm{E}_{c}$, and $\mathrm{G}_{c}$, or the total operating cost $\mathrm{T}_{c}$. 


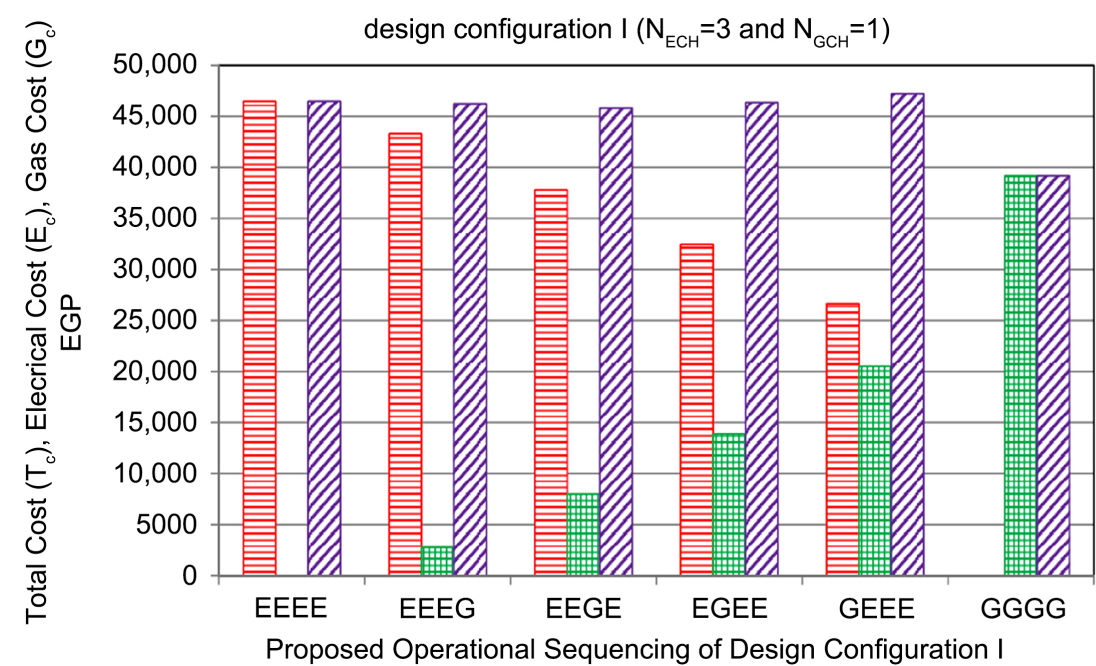

目 Electrical Cost

田Gas Cost

G Total Cost

(a)

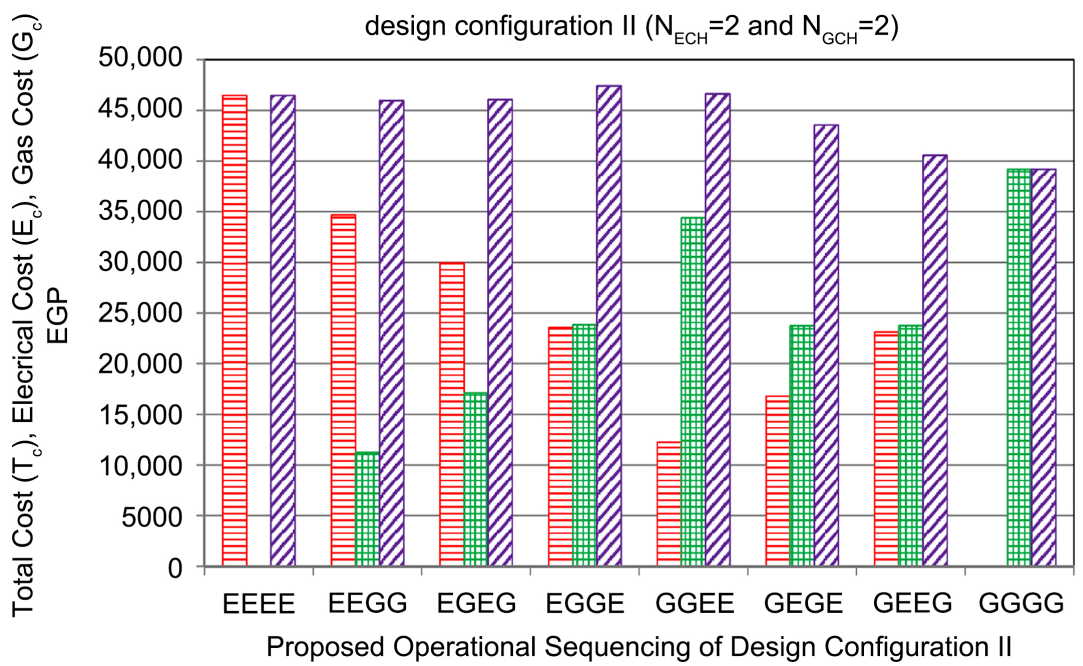

日Electrical Cost

田 Gas Cost

$\square$ Total Cost

(b)

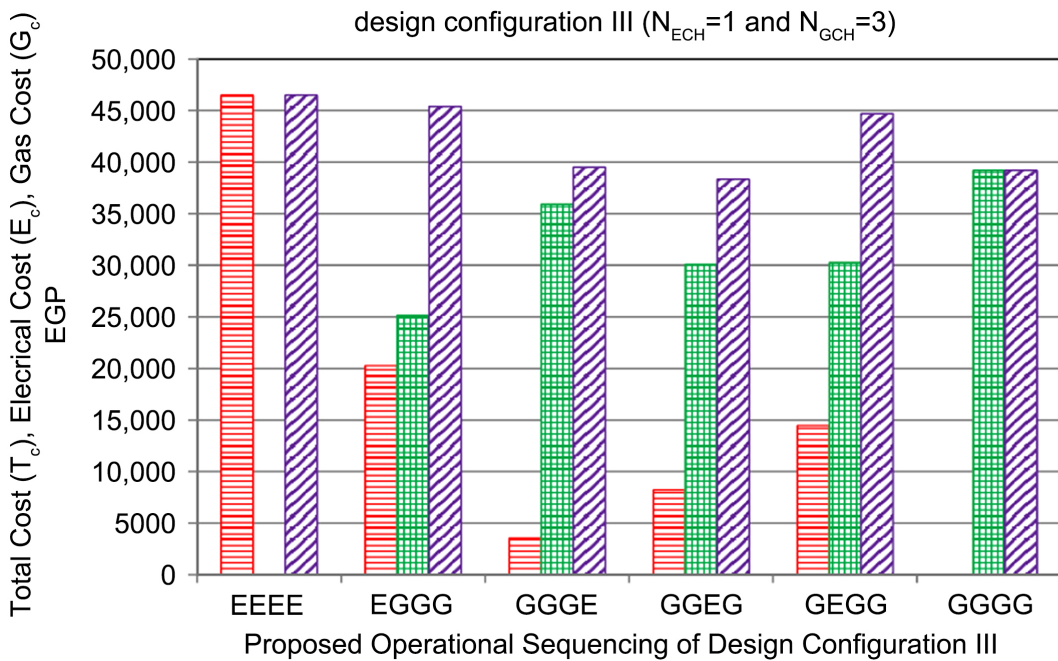

$\boxminus$ Electrical Cost

ד Gas Cost

च Total Cost

(c)

Figure 10. Operational cost components of electrical cost, gas cost, and total cost for three design options (a) $2 \mathrm{ECHs}+2 \mathrm{GCHs}$, (b) $3 \mathrm{ECHs}+1 \mathrm{GCH}$, and (c) $1 \mathrm{ECH}+3 \mathrm{GCH}$. 


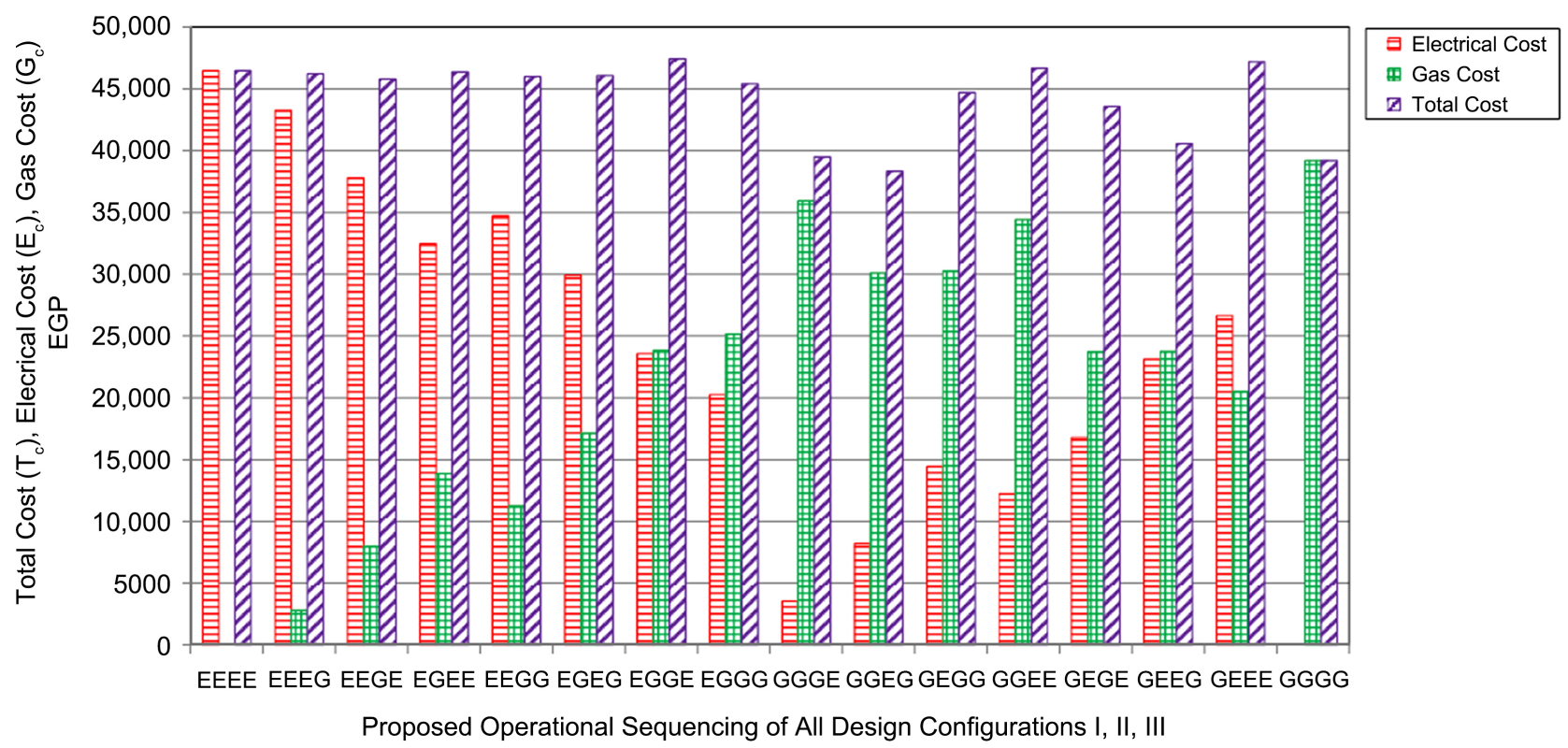

Figure 11. Operational cost components of electrical cost, gas cost, and total cost in EGPs for all design options and all operational sequences.

\subsection{Results of $\mathrm{COP}_{\mathrm{HCP}, \text { app }}$}

Figure 12 displays the apparent coefficient of performance for $\mathrm{HCP}\left(\mathrm{COP}_{\mathrm{HCP}, \mathrm{app}}\right)$ for all design configurations and all operational sequencing. Figure 12 compares the values of $\mathrm{COP}_{\mathrm{HCP}, \text { app }}$ estimated using Equation (2) for all numerically investigated experiments for all design configurations and operational sequences. The results shown in Figure 12 indicate that the maximum value for $\mathrm{COP}_{\mathrm{HCP}, \mathrm{app}}$ is recorded for EEEG at 5.1, and on the other extreme the minimum value for $\mathrm{COP}_{\mathrm{HCP}, \text { app }}$ is observed for GGGE at 2.06. it should be clear that these values confirm those depicted in Table 3, listed above. The $\mathrm{COP}_{\mathrm{HCP}, \text { app }}$ values increase gradually from both sides left and right of the minimum value recorded at GGGE. It should be noted that this operating sequence GGGE, has recorded the minimum value of $E_{c}$ and the maximum value of $G_{c}$, as can be seen from Figure 11. Figure 12 is another helpful tool for both the building cooling systems designers and the building operators to select the optimal design and optimal operating sequences to maximize the value of the apparent coefficient of performance for $\mathrm{HCP}\left(\mathrm{COP}_{\mathrm{HCP}, \mathrm{app}}\right)$. Similar to Figure 11 which summarizes the results of operational running cost components and total running cost, Figure 12 summarizes the results of the apparent coefficient of performance for HCP $\left(\mathrm{COP}_{\mathrm{HCP,app}}\right)$ for all design configurations and operational sequences.

\subsection{Effects of HCP Design Configuration on HCP}

This subsection gives an overview of the first factor which has an influence on HCP economics and thermal performance, which is the design configurations. The results reveal that design configurations control the economic factors of HCP either during the design stage and the initial cost of the HCP $\left(\mathrm{I}_{\mathrm{c}}\right)$ or during 


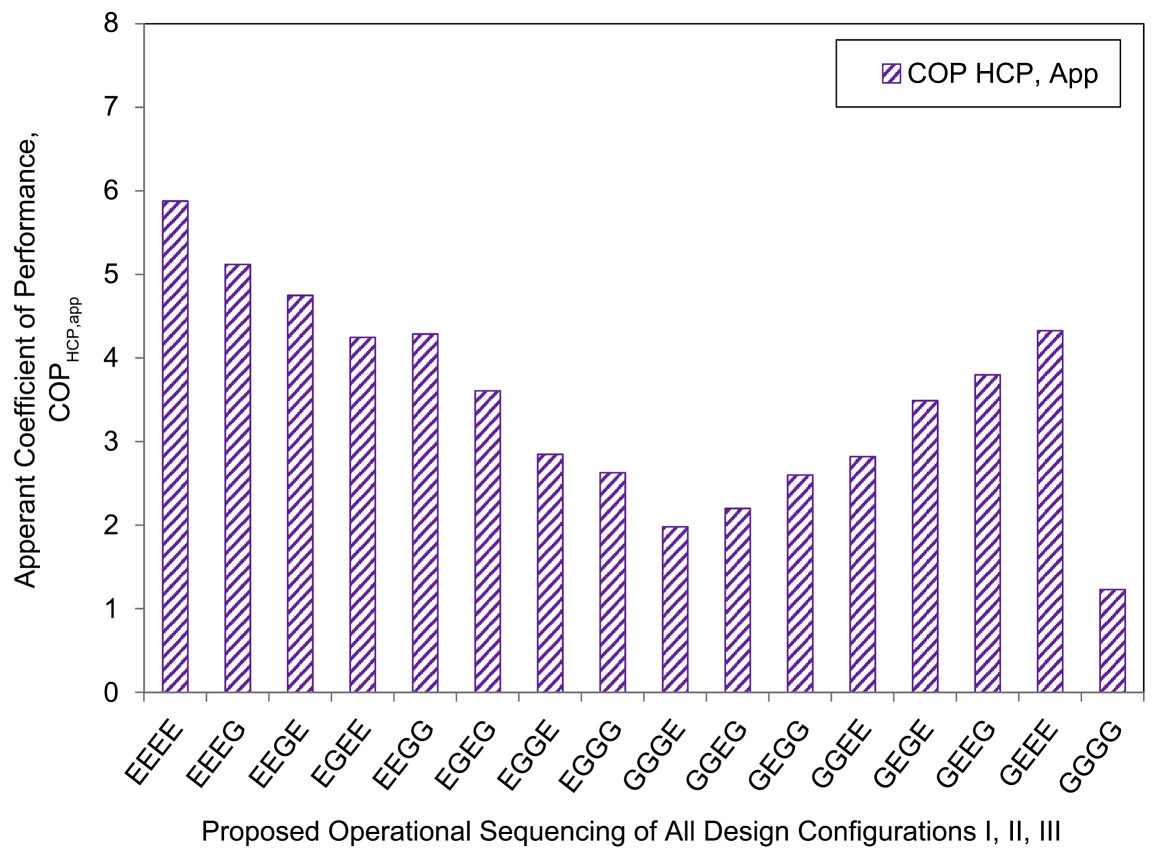

Figure 12. Apparent coefficient of performance ( $\left.\mathrm{COP}_{\mathrm{HCP}, \mathrm{app}}\right)$ for $\mathrm{HCP}$ for all design options and all operational sequencing.

the operation stage by controlling and limiting for electrical cost $\mathrm{E}_{c}$, gas $\operatorname{cost} \mathrm{G}_{c}$, and total cost $T_{c}$ in EGPs. Both Table 3 and Figure 7 depict that the $I_{c}$ values of the proposed design configurations I, II, and III for HCP are classified into three initial cost values which are 27, 35, and 41 million EGPs, respectively.

Similarly, both Table 3 and Figure 11 summarize that the values of electrical cost $E_{c}$, gas cost $G_{c}$, and total cost $T_{c}$ in EGPs of the design configurations I, II, and III for HCP fluctuate up on both design configurations and also on their operational sequences. However for the apparent coefficient of performance for HCP ( $\mathrm{COP}_{\mathrm{HCP}, a \mathrm{p} p}$ ), both Table 3 and Figure 12 summarize that the values of $\mathrm{COP}_{\mathrm{HCP} \text {,app }}$ for the design configurations I, II, and III fluctuate by increasing or decreasing up on both design configurations and also on their operational sequences. It should be clear from the results presented in this article that the proposed design configurations I, II, and III for HCP highly influence both HCP economics and thermal performance of the HCP.

\subsection{Effects of Operating Sequences on HCP Performance}

This subsection gives an overview of the second factor which has an influence on HCP economics and thermal performance, which is the operating sequences. The results reveal that operating sequences control the economic factors of HCP during the operation stage by controlling and limiting electrical cost $\mathrm{E}_{\mathrm{c}}$, gas cost $\mathrm{G}_{c}$, and total cost $\mathrm{T}_{\mathrm{c}}$ in EGPs. Both Table 3 and Figure 11 summarize that the values of electrical cost $E_{c}$, gas cost $G_{c}$, and total cost $T_{c}$ in EGPs of the operating sequences for design configurations I, II, and III for HCP fluctuate up on both designs configurations and also on their operational sequences. However for the 
apparent coefficient of performance for $\mathrm{HCP}\left(\mathrm{COP}_{\mathrm{HCP}, \text { app }}\right)$, both Table 3 and Figure 12 summarize that the values of $\mathrm{COP}_{\mathrm{HCP} \text {,app }}$ for the design configurations I, II, and III fluctuate by increasing or decreasing up on both design configurations and also on their operational sequences. It should be clear from the results presented in this article that the proposed operational sequences for all design configurations I, II, and III for HCP highly influence on both HCP economics and thermal performance of the HCP. The current study gives deep insight into understanding the benefits of HCP with different operational sequences and design configurations on both economics and thermal performance.

\section{Conclusions}

This study discusses how numerical models with several design options facilitate different operating sequences with significant change for all economic factors and thermal performance. The results of operational cost components conclude that electrical cost $E_{c}$, gas cost $G_{c}$, and total cost $T_{c}$ in EGPs are three important factors to control the selection of design options, discussed in this articles as configuration I, II, III. The results conclude that the apparent coefficient of performance $\mathrm{COP}_{\mathrm{HCP} \text {,app }}$ for $\mathrm{HCP}$ could be improved by both optimal selections of design configuration by architecture and mechanical designers, and during the operation by building operators.

The novelty of this study introduces economical and energy-saving comparative studies to assess and optimize the performance of several design options with a large number of operational sequences to facilitate wide selection mapping for the two main axes regarding both economics and thermal performance. The optimization between both the operational cost components $\left(E_{c}, G_{c}\right.$, and $\left.T_{c}\right)$ in EGPs and the apparent coefficient of performance $\mathrm{COP}_{\mathrm{HCP}, a p p}$ for HCP is strengthened by using the proposed methodologies for design configurations with the numerically investigated operating sequences. These findings limit and control many of the physical and operating constraints of the hybrid chiller plant HCP. The present optimization focuses on rectifying the design configuration by adopting the operational sequence according to the energy resources and any expected fluctuations in their costs. Further electricity-savings and gas-saving would be achieved by selecting the optimal design configuration and also during the operation stage by selecting the optimum operating sequence.

The future research work will ascertain the improvement of the numerical models to optimize hybrid chiller plant operating sequence using fuzzy assignment problem-solving techniques under the uncertainty of the building cooling load profile.

\section{Conflicts of Interest}

The authors declare no conflicts of interest regarding the publication of this paper. 


\section{References}

[1] Smith, B. (2002) Economic Analysis of Hybrid Chiller Plants. ASHARE Journal, 44, 42-45.

[2] Bodach, S., Lang, W. and Auer, T. (2016) Design Guidelines for Energy-Efficient Hotels in Nepal. International Journal of Sustainable Built Environment, 5, 411-434. https://doi.org/10.1016/j.ijsbe.2016.05.008

[3] Deng, S. and Burnett, J. (2000) A Study of Energy Performance of Hotel Buildings in Hong Kong. https://doi.org/10.1016/S0378-7788(98)00067-X

[4] Mardani, A., Jusoh, A., Bagheri, M.M. and Kazemilari, M. (2015) A Combined Hybrid Fuzzy Multiple Criteria Decision-Making Approach to Evaluating of QM Critical Success Factors in SME's Hotels Firms. Procedia Social and Behavioral Sciences, 172, 786-793. https://doi.org/10.1016/j.sbspro.2015.01.433

[5] Sheng, Y., Miao, Z., Zhang, J., Lin, X. and Ma, H. (2018) Energy \& Buildings Energy Consumption Model and Energy Benchmarks of Five-Star Hotels in China. Energy and Buildings, 165, 286-292. https://doi.org/10.1016/j.enbuild.2018.01.031

[6] Jasmim, M., Sampaio, M.C. and Costa, H.G. (2020) Criteria for Assessing a Sustainable Hotel Business. Journal of Cleaner Production, 262, Article ID: 121347. https://doi.org/10.1016/j.jclepro.2020.121347

[7] Kyriaki, E., Giama, E., Papadopoulou, A., Drosou, V. and Papadopoulos, A.M. (2017) Energy and Environmental Performance of Solar Thermal Systems in Hotel Buildings. Procedia Environmental Sciences, 38, 36-43. https://doi.org/10.1016/j.proenv.2017.03.072

[8] Buso, T. and Corgnati, S.P. (2017) A Customized Modelling Approach for Multi-Functional Buildings-Application to an Italian Reference Hotel. Applied Energy, 190, 1302-1315. https://doi.org/10.1016/j.apenergy.2017.01.042

[9] Kresteniti, A. (2017) Development of a Concept for Energy Optimization of Existing Greek Hotel Buildings. Procedia Environmental Sciences, 38, 290-297. https://doi.org/10.1016/j.proenv.2017.03.080

[10] Xing, J., Ren, P. and Ling, J. (2015) Analysis of Energy Efficiency Retrofit Scheme for Hotel Buildings Using eQuest Software: A Case Study from Tianjin, China. Energy and Buildings, 87, 14-24. https://doi.org/10.1016/j.enbuild.2014.10.045

[11] Rajagopalan, P., et al. (2009) A Study on Energy Performance of Hotel Buildings in Singapore. Energy and Buildings, 41, 1319-1324. https://doi.org/10.1016/j.enbuild.2009.07.028

[12] Yang, C., Wang, X., Huang, M., et al. (2017) Design and Simulation of Gas Turbine-Based CCHP Combined with Solar and Compressed Air Energy Storage in a Hotel Building. Energy and Buildings, 153, 412-420. https://doi.org/10.1016/j.enbuild.2017.08.035

[13] Hafeez, M., Nasir, A. and Hassan, A.S. (2020) Thermal Performance of Double Brick Wall Construction on the Building Envelope of High-Rise Hotel in Malaysia. Journal of Building Engineering, 31, Article ID: 101389. https://doi.org/10.1016/j.jobe.2020.101389

[14] Wang, J.C. (2012) A Study on the Energy Performance of Hotel Buildings in Taiwan. Energy and Buildings, 49, 268-275. https://doi.org/10.1016/j.enbuild.2012.02.016

[15] Chung, M. and Park, H. (2015) Comparison of Building Energy Demand for Hotels, Hospitals, and Offices in Korea. Energy, 92, 383-393.

https://doi.org/10.1016/j.energy.2015.04.016 
[16] Gonc, P., Gaspar, A.R. and Gameiro, M. (2012) Energy and Exergy-Based Indicators for the Energy Performance Assessment of a Hotel Building. Energy and Buildings, 52, 181-188. https://doi.org/10.1016/j.enbuild.2012.06.011

[17] Cheng, Q., Wang, S., Yan, C. and Xiao, F. (2017) Probabilistic Approach for Uncertainty-Based Optimal Design of Chiller Plants in Buildings. Applied Energy, 185, 1613-1624. https://doi.org/10.1016/j.apenergy.2015.10.097

[18] Karami, M. and Wang, L. (2018) Particle Swarm Optimization for Control Operation of an All-Variable Speed Water-Cooled Chiller Plant. Applied Thermal Engineering, 130, 962-978. https://doi.org/10.1016/j.applthermaleng.2017.11.037

[19] Wang, H. (2017) Empirical Model for Evaluating Power Consumption of Centrifugal Chillers. Energy and Buildings, 140, 359-370.

https://doi.org/10.1016/j.enbuild.2017.02.019

[20] Wang, H. (2017) A Steady-State Empirical Model for Evaluating Energy Efficient Performance of Centrifugal Water Chillers. Energy and Buildings, 154, 415-429. https://doi.org/10.1016/j.enbuild.2017.08.072

[21] Yu, F.W. and Chan, K.T. (2012) Assessment of Operating Performance of Chiller Systems Using Cluster Analysis. International Journal of Thermal Sciences, 53, 148-155. https://doi.org/10.1016/j.ijthermalsci.2011.10.009

[22] Zheng, Z., Li, J. and Duan, P. (2019) Optimal Chiller Loading by Improved Artificial Fish Swarm Algorithm for Energy Saving. Mathematics and Computers in Simulation, 155, 227-243. https://doi.org/10.1016/j.matcom.2018.04.013

[23] Zhuang, C., Wang, S. and Shan, K. (2020) A Risk-Based Robust Optimal Chiller Sequencing Control Strategy for Energy-Efficient Operation Considering Measurement Uncertainties. Applied Energy, 280, Article ID: 115983. https://doi.org/10.1016/j.apenergy.2020.115983

[24] Liao, Y., Huang, G., Sun, Y. and Zhang, L. (2014) Uncertainty Analysis for Chiller Sequencing Control. Energy and Buildings, 85, 187-198.

https://doi.org/10.1016/j.enbuild.2014.09.037

[25] Liao, Y., Huang, G., Ding, Y., Wu, H. and Feng, Z. (2018) Robustness Enhancement for Chiller Sequencing Control under Uncertainty. Applied Thermal Engineering, 141, 811-818. https://doi.org/10.1016/j.applthermaleng.2018.06.031

[26] Lu, J., Chang, Y. and Ho, C. (2015) The Optimization of Chiller Loading by Adaptive Neuro-Fuzzy Inference System and Genetic Algorithms. Mathematical Problems in Engineering, 2015, Article ID: 306401. https://doi.org/10.1155/2015/306401

[27] Shirazi, A., Taylor, R.A., Morrison, G.L. and White, S.D. (2018) Solar-Powered Absorption Chillers: A Comprehensive and Critical Review. Energy Conversion and Management, 171, 59-81. https://doi.org/10.1016/j.enconman.2018.05.091

[28] Afzali, S.F. and Mahalec, V. (2017) Optimal Design, Operation and Analytical Criteria for Determining Optimal Operating Modes of a CCHP with Fired HRSG, Boiler, Electric Chiller and Absorption Chiller. Energy, 139, 1052-1065. https://doi.org/10.1016/j.energy.2017.08.029

[29] Ho, W.T. and Yu, F.W. (2021) Improved Model and Optimization for the Energy Performance of Chiller System with Diverse Component Staging. Energy, 217, article ID: 119376. https://doi.org/10.1016/j.energy.2020.119376

[30] Li, X. and Yao, R. (2021) Modelling Heating and Cooling Energy Demand for Building Stock Using a Hybrid Approach. Energy and Buildings, 235, Article ID: 110740. https://doi.org/10.1016/j.enbuild.2021.110740

[31] Yu, F.W. and Chan, K.T. (2007) Optimum Load Sharing Strategy for Mul- 
tiple-Chiller Systems Serving Air-Conditioned Buildings. Building and Environment, 42, 1581-1593. https://doi.org/10.1016/j.buildenv.2006.01.006

[32] YK Style H Centrifugal Liquid Chiller Engineering Guide (Form 160.76-EG1). https://cgproducts.johnsoncontrols.com/YorkDoc/160.76-EG1.pdf

[33] What Makes the Non-Electric Absorption Chiller from BROAD So Energy Efficient?

https://www.broadusa.net/en/wp-content/uploads/2020/01/Why-are-non-elec-chill ers-energy-efficient.jpeg 


\section{Nomenclature}

\begin{tabular}{|c|c|c|}
\hline $\mathrm{COP}_{\mathrm{ECH}}$ & coefficient of performance for electrical driven chiller & $(\quad)$ \\
\hline $\mathrm{COP}_{\mathrm{GCH}}$ & coefficient of performance for gas driven chiller & $(\quad)$ \\
\hline $\mathrm{COP}_{\mathrm{HCP}}$ & coefficient of performance for hybrid chiller plant & $(\quad)$ \\
\hline $\mathrm{E}_{\mathrm{c}}$ & electrical energy cost & (EGP) \\
\hline $\mathrm{G}_{\mathrm{c}}$ & natural gas cost & $(\mathrm{EGP})$ \\
\hline$I_{c}$ & Initial cost per chiller & $(\mathrm{EGP})$ \\
\hline $\mathrm{N}_{\mathrm{ECH}}$ & number of electrical driven chillers & (chiller) \\
\hline $\mathrm{N}_{\mathrm{GCH}}$ & number of gas driven chillers & (chiller) \\
\hline $\mathrm{P}_{\text {comp }}$ & centrifugal compressor power & $(\mathrm{kW})$ \\
\hline $\mathrm{P}_{\text {pump }}$ & solute pump power & $(\mathrm{kW})$ \\
\hline $\mathrm{Q}_{\mathrm{cc}}$ & cooling capacity & $(\mathrm{TR})$ \\
\hline $\mathrm{t}$ & time & $(\mathrm{hr})$ \\
\hline $\mathrm{T}$ & temperature & $\left({ }^{\circ} \mathrm{C}\right)$ \\
\hline $\mathrm{T}_{\mathrm{c}}$ & total running cost, $\left(\mathrm{E}_{\mathrm{c}}+\mathrm{G}_{\mathrm{c}}+\mathrm{W}_{\mathrm{c}}\right)$ & $(\mathrm{EGP})$ \\
\hline $\mathrm{V}_{{ }_{\mathrm{NG}}}$ & natural gas volume flow rate & $\left(\mathrm{m}^{3} / \mathrm{hr}\right)$ \\
\hline $\mathrm{W}_{\mathrm{c}}$ & water cost & (EGP) \\
\hline
\end{tabular}

\section{Greek Symbol}

\begin{tabular}{lll}
\hline$\eta_{\text {exergetic }}$ & exergetic efficiency & $(\%)$ \\
$\tau$ & chiller duty hours & $(\%)$ \\
\hline
\end{tabular}

\section{Subscripts}

\begin{tabular}{llll}
\hline cc & cooling capacity & chwr & chilled water return \\
chws & chilled water supply & comp & compressor \\
cond & condensing & ECH & electric driven chiller \\
evap & evaporating & GCH & gas driven chiller \\
HCP & hybrid chiller plant & chws & chilled water supply \\
cwr & cooling water return & cws & cooling water supply \\
pump & solute circulating pump & NG & natural gas \\
\hline
\end{tabular}

\section{Abbreviations}

\begin{tabular}{llll}
\hline CHWP & chilled water pump & COP & coefficient of performance \\
CT & cooling tower & CWP & cooling water pump \\
ECH & Electrical-drivenchiller & EGP & Egyptian Pound \\
GCH & Gas-driven chiller & HCP & hybrid chiller Plant \\
HFC & Hydro Fluoro Carbon & HFC-134a & Chlorodifluoromethane \\
Li-Br & Lithium Bromide & N/A & not available \\
NGRV & NG regulator valve & TR & refrigeration tonnage \\
USD & United States Dollar & VSD & Variable Speed Drive
\end{tabular}

